\title{
The physiological roles of the boar ejaculate
}

H. Rodríguez-Martínez', U. Kvist' ${ }^{2}$, F. Saravia ${ }^{1 a}$, M. Wallgren ${ }^{1,3}$, A. Johannisson ${ }^{4}$, L. Sanz ${ }^{5}$, F.J. Peña ${ }^{6}$, E.A. Martínez', J. Roca7, J.M. Vázquez' and J.J. Calvete ${ }^{5}$

'Division of Reproduction, Faculty of Veterinary Medicine \& Animal Science (FVMAS), Swedish University of Agricultural Sciences (SLU), POB 7054, SE-75007 Uppsala, Sweden; ${ }^{2}$ Center for Andrology \& Sexual Medicine, Department of Medicine, Karolinska University Hospital/Huddinge, SE-14186 Stockholm, Sweden; ${ }^{3}$ Quality Cenetics, Räby 2004, SE-24292 Hörby, Sweden; ${ }^{4}$ Department of Anatomy, Physiology \& Biochemistry, FVMAS, SLU, POB 7011, SE-75007 Uppsala, Sweden;

sLaboratory of Structural Proteomics, Institute of Biomedicine of Valencia, CSIC, laime Roig 11 , 46010 Valencia, Spain; 'Section of Reproduction \& Obstetrics, Department of Medicine, Faculty of Veterinary Medicine, Avd de la Universidad s/n, 10071 Cáceres, Spain; 'Department of Medicine \& Animal Surgery, Faculty of Veterinary Science, University of Murcia, Campus de Espinardo, 30100 Murcia, Spain; ${ }^{2}$ Current address: Dept of Animal Sciences, Faculty of Veterinary Sciences, University of Concepción, Av. Vicente Mendez 595, Chillán, Chile

During ejaculation in the boar, sperm cohorts emitted in epididymal cauda fluid are sequentially exposed and resuspended in different mixtures of accessory sex gland secretion. This paper reviews the relevance of such unevenly composed fractions of seminal plasma (SP) in vivo on sperm transport and sperm function and how this knowledge could benefit boar semen processing for artificial insemination (AI). The firstly ejaculated spermatozoa (first $10 \mathrm{ml}$ of the sperm-rich fraction, SRF [P1]) remain mainly exposed to epididymal cauda fluid and its specific proteins i.e. various lipocalins, including the fertility-related prostaglandin D synthase; than to prostatic and initial vesicular gland secretions. P1spermatozoa are hence exposed to less bicarbonate, zinc or fructose and mainly to PSP-I spermadhesin; than if they were in the rest of the SRF and the post-SRF (P2). Since the P1-SP is less destabilizing for sperm membrane and chromatin, P1-spermatozoa sustain most in vitro procedures, including cryopreservation, the best. Moreover, ejaculated firstly, the P1-spermatozoa seem also those deposited by the boar as a vanguard cohort, thus becoming overrepresented in the oviductal sperm reservoir (SR). This vanguard SR-entry occurs before the endometrial signalling of SP components (as PSP-l/PSP-II and cytokines) causes a massive influx of the innate defensive PMNs to cleanse the uterus from eventual pathogens, superfluous spermatozoa and the allogeneic SP. The $\mathrm{SP}$ also conditions the mucosal immunity of the female genital tract, to tolerate the SR-spermatozoa and the semi-allogeneic conceptus. These in vivo gathered data can be extrapolated into procedures for handling boar spermatozoa in vitro for $\mathrm{Al}$ and other biotechnologies, including simplified cryopreservation. 


\section{Introduction}

Modern pig production is vertically integrated, with breeding done through Al. This firstline, easy, practical and highly effective biotechnology serves two major purposes (i) avoid spreading venereal (or otherwise semen-shed) diseases and, (ii) maximise dissemination of genetic material to large numbers of sows. With proper detection of oestrus (twice daily) and Al correctly performed $(80-100 \mathrm{~mL}$, cervical, $2-3$ times/oestrus) with high-quality semen ( $>2$ $\times 10^{9}$ motile spermatozoa), $>90 \%$ of farrowing rates and mean litter sizes of $12-14$ piglets are reached, comparable with those achieved with natural mating (reviewed by Rodriguez-Martínez 2007a). With such results, it is not surprising that pig Al became an essential breeding tool, increasing worldwide from $\sim 7 \%$ at the start of the 1980 s (Reed 1985) to more than $80 \% 20$ years later (Wagner \& Thibier 2000). In the European Union (EU) $\sim 84 \%$ of all sows/gilts are bred by Al (Feitsma, personal communication).

Improvements in the design of media, Al-catheters and moment of $\mathrm{Al}$, have led to $>99 \%$ of alt Als done around the world being made with liquid semen (Wagner \& Thibier 2000). Frozenthawed $(\mathrm{FT})$ semen is, however, rarely used ( $\sim 1 \%$, Thibier, personal communication), since cryopreservation is still considered "quasi experimental". However, breeding enterprises are interested in further developing cryopreservation, since FT-semen could be used in situations in which the widely used liquid semen can not, such as the international exchange of genetic lines without transporting livestock, the long-term conservation of superior genetic individuals in genetic resource banks, or the testing for presence of pathogens before use. Yet, boar spermatozoa show low cryosurvival $(\sim 40 \%)$ and a shortened lifespan among surviving spermatozoa. This obviously leads to lower farrowing rates and smaller litter sizes compared to liquid semen (reviewed by Rodríguez-Martínez 2007a). Moreover, cryopreservation procedures are cumbersome, timeconsuming and yield few doses/ejaculate, all of which deter from its wider use.

Ongoing research aims to widen Al-use, by decreasing sperm numbers per Al-dose (increasing extension), designing novel media (chemically-defined) or quicker cryopreservation methods, and implementing alternative procedures for semen deposition (intra-uterine). Despite gains thus far (rev by Rodríguez-Martínez 2007a), innate characteristics of the boar ejaculate such as the specifics of the sperm structure and of the seminal plasma (SP), yet hinder full success. The SP is not just a sperm vehicle, but as relevant modulator for sperm function, for sperm transport post-breeding and as inductor of both innate and adaptive immunological responses by the female that would ensure reproductive success. Considering the current focus for novel semen extension and sperm treatments for $\mathrm{Al}$, the present paper attempts to review aspects of the characteristics of the boar ejaculate in relation to sperm transport in the female genitalia in vivo, and how this knowledge could benefit boar semen processing for Al.

\section{Ejaculation in the pig}

Ejaculation is a highly coordinated physiological process involving neurological and muscular events that build two distinct phases; (i) emission (the formation and deposition of semen [spermatozoa and seminal fluid] in the urethra and (ii) the forthcoming ejection of the semen through the penis urethra (the so-called expulsion, or ejaculation proper). In boars, emission and ejaculation repeat as waves for 5-10 min, during which the complete ejaculate $(250-300 \mathrm{ml}$ in a mature boar) is sequentially verted into the female cervix lumen or it is manually collected ex-corpore into a recipient (Senger 2005). In the latter case, waves can be regarded by the operator as a sequence of three major fractions. These fractions are classically called pre-sperm (PSF, with a clear seminal fluid, some gel and a heavy degree of contamination of cell debris, urine and smegma from the preputium), sperm-rich (SRF, easily recognised by its creamy-white colour) and post sperm-rich (PSRF, that goes from greyish to watery 
in aspect) and whose increasing amounts of "tapioca-like" flocula, signals the end of the ejaculation process, accompanied by a fading of the penile erection. Interestingly, a second ejaculation sequence can be manually stimulated with brief, firm, pulsating hand pressure applied to the penis, upon which a new, but smaller, SRF is often collectable (Mann \& Lutwak-Mann 1981).

\section{The ejaculate of the boar}

The ejaculate is a sperm suspension $\left(\sim 50-90 \times 10^{9}\right.$ in 9 month-old boars to $\sim 70-110 \times 10^{9}$ when they reach maturity, i.e. after 12 months of age; Flowers 2008, Wallgren, unpublished results) in a SP composed of the mixture of the contents of the tails of the ductus epididymides and the secretions of the accessory sexual glands. The latter vary in content, volume and occurrence of excretion, building fractions of different composition. The PSF-SP contains mainly secretion of the urethral and bulbourethral glands, as well as of prostate; the SRF-SP is a blend SP where the emitted epididymal fluid in which spermatozoa (see Fig. 1) originally bathe, is diluted in vesicular gland and prostate secretions. Lastly, the PSRF-SP suspends few spermatozoa, being a fluid primarily derived from the increasing secretion of the vesicular glands, the prostate and, by the end of the ejaculation, the bulbourethral glands (Einarsson 1971, Mann \& Lutwak-Mann 1981). The latter delivers a tapioca-like flocular secretion that coagulates in contact with the vesicular fluid the SP, as seen when the entire ejaculate is collected in an open recipient. The role of this process is, in vivo, to retain the ejaculate in utero, minimizing the transcervical backflow commonly seen at Al with liquid semen, where the gel component is consistently filtered away (Viring \& Einarsson 1981). Spermatozoa are, therefore, ejaculated with a maximum peak concentration in the first portion of the SRF (i.e. the first 10-15 ml, called Portion 1 or P1, an easily collectable portion; Rodriguez-Martinez et al. 2005, Fig. 1), decreasing thereafter in numbers along this fraction to virtually disappear by the PSRF alongside with increasing secretion of the vesicular glands.

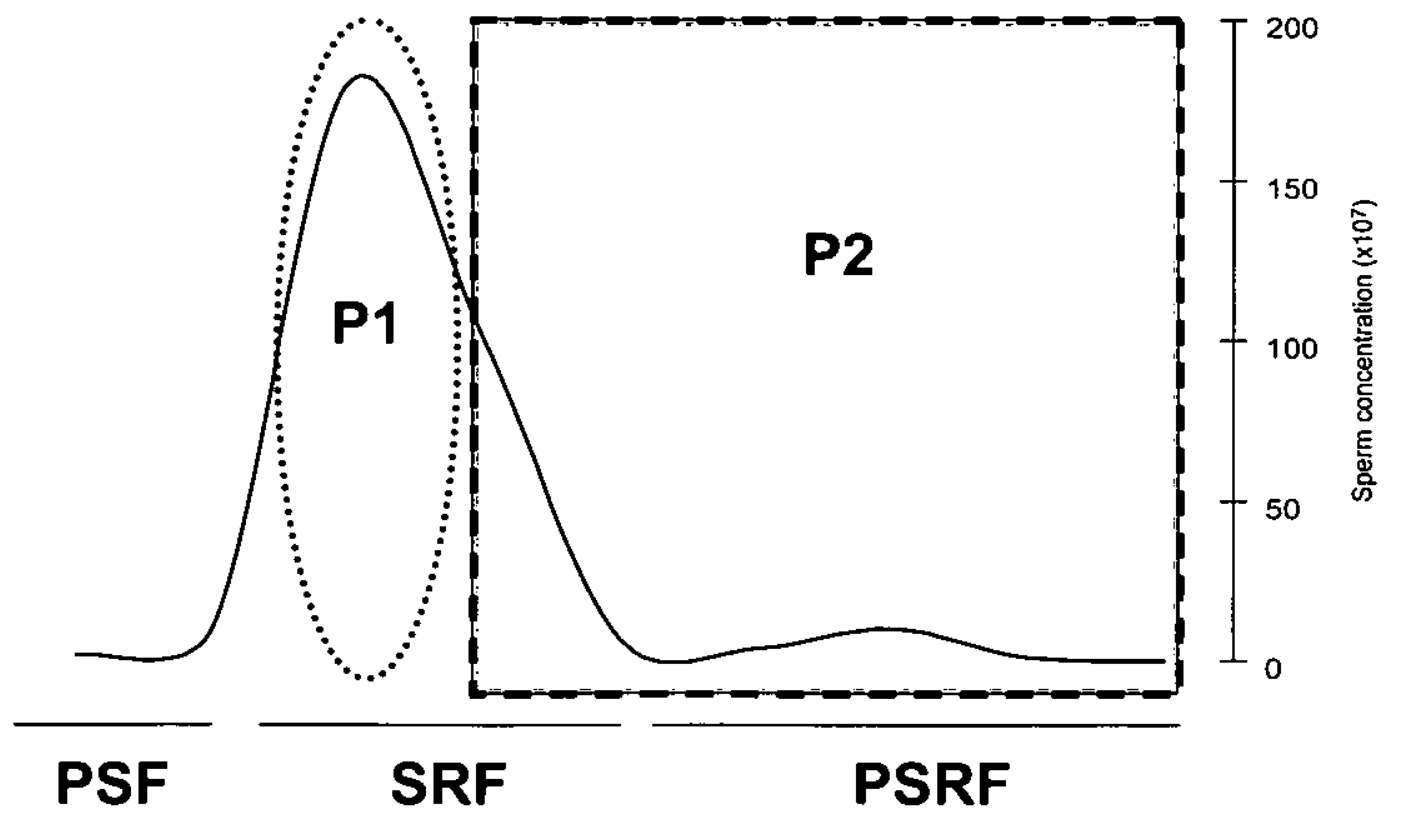

Fig. 1 Relative sperm concentrations (- - define ejaculate fractions in the boar ejaculate (PSF: pre-sperm fraction, SRF: sperm-rich fraction, PSRF: post sperm-rich fraction (includes gel component). Portions of the ejaculate can also be defined; P1: 1 st $10 \mathrm{ml}$ of the SRF, P2: the rest of the SRF and the PSRF. 


\section{The boar seminal plasma, a heterogenous fluid}

Most studies of the boar SP have been done as bulk fluid (since this is the way the ejaculate has been sampled), but there are excellent studies of fractionated samples (Einarsson 1971, Lavon \& Boursnell 1975), which have shown that, owing to its sequential formation, the SP contains many components, all of which interact with spermatozoa and the surrounding female environment. The PSF has mostly electrolytes (mainly $\mathrm{Na}$ and $\mathrm{Cl}$ ); the SRF mainly proteins but also steroid hormones (Claus et al. 1987, Claus 1990), glycerophosphorylcholine, fructose, glucose, inositol, citrate, bicarbonate and zinc, while the PSRF has increasing amounts of proteins, bicarbonate, zinc, $\mathrm{Na}, \mathrm{Cl}$ and sialic acid (summarised by Mann \& Lutwak-Mann 1981).

The source of the steroid hormones found in the boar ejaculate varies. Most testosterone derives from the accessory sexual glands, while oestrogens are mainly (80-90\%) introduced in semen by the epididymal contents (originally testicular; Claus 1990 and references therein). Oestrogens, which in the boar can reach $>10 \mu \mathrm{g} / \mathrm{ejaculate}$, stimulate the myometrium directly or indirectly (through induction of endometrial $P\left(F_{2 \alpha}\right.$ ), as well as by influencing the release of LH (Claus 1990). Therefore, SP-oestrogens are considered important, along with the behavioural, neuronal release of oxytocin; for the coordinated, long-lasting uterine motility during oestrus which issues the rapid phase of sperm transport in the female (Langendijk et al. 2005) and, ultimately, fertility (Claus et al. 1989).

Proteins are a major component of the boar ejaculate $(39.4 \pm 13.45 \mathrm{mg} / \mathrm{ml}$, Rodriguez-Matinez et al. 2005), $80-90 \%$ of vesicular gland origin and $75-90 \%$ of them belonging to the spermadhesin lectin family. This family comprises three members; the Alanine-Glutamine-Asparagine proteins AQN (-1 and -3), the Alanine-Tryptophan-Asparagine proteins [AWNs] and the Porcine Seminal Plasma proteins I and II [PSP-I and PSP-II] (Töpfer-Petersen et al. 1998). Spermadhesins are multifunctional 12-16 kDa glycoproteins whose biological activities depend on their sequence, grade of glycosylation or aggregation state, as well as their ability to bind heparin (the AQN-1, $A Q N-3$ and $A W N$ being grouped as heparin-binding proteins [HBPs]) or not (PSPs), as they attach to the sperm plasma membrane to various degrees from the testis to the ejaculate. Collectively, they have been related to multiple effects on spermatozoa including membrane stabilisation, capacitation, and sperm-oviduct or zona pellucida (ZP) interplay. HBPs seem to stabilise the supraacrosomal plasmalemma prior to capacitation in vivo (Calvete et al. 1997). AWN-epitopes have been detected on boar spermatozoa bound in vivo to the $Z P$, strongly suggesting $A W N$ is a bona fide sperm surface-associated lectin, mediating sperm-ZP interactions at fertilisation (RodriguezMartinez et al. 1998). In vitro, however, HBPs failed to promote sperm survival (Centurión et al. 2003), while PSPs, also binding to the sperm surface (Töpfer-Petersen et al. 1998), display protective action on highly-extended and processed spermatozoa (Caballero et al. 2004, 2006, 2008 and references therein). The PSP-I and PSP-II account for $>50 \%$ of all SP-proteins, forming a non-heparin-binding heterodimer of glycosylated spermadhesins (Calvete et al. 2005) which depict immunostimulatory activities in vitro (Leshin et al. 1998) and in vivo (Rodríguez-Martínez et al. 2005). The various SP proteins originate from the testis, the epididymides and the sexual accessory glands (García et al. 2008), and their relative concentration vary among ejaculate fractions (see Fig. 2). Expectedly, the amounts of proteins increase 4-fold alongside the secretion of the vesicular glands, the relative concentrations thus being lowest P1, to increase (HBPs and, particularly the PSPS) towards the bulk of the PSRF (Rodriguez-Martinez et al. 2005), implying that the major proportion of spermatozoa is not immediately suspended in high amounts of SP-proteins in vivo, particularly not those firstly ejaculated.

Bicarbonate, an ion considered highly relevant for sperm motility, for induction of destabilisation changes in the plasma membrane and, ultimately, for in vitro and in vivo capacitation (reviewed by Rodríguez-Martínez 2007b), is present in the bulk boar ejaculate (20-23 mM/l). Concentration varies among fractions, from $14-17 \mathrm{mmol} / \mathrm{I}$ in the PSF and SRF, respectively, to the double i.e. 
$>30 \mathrm{mmol} / \mathrm{l}$, in the PSRF (Rodríguez-Martínez et al. 1990b). Bicarbonate levels are lowest in the P1 ( $13 \mathrm{mmol} / \mathrm{l}$ ) (Saravia et al. unpublished, Fig. 3), e.g. the first cohort of ejaculated P1spermatozoa does not bathe in a SP with high levels of bicarbonate.

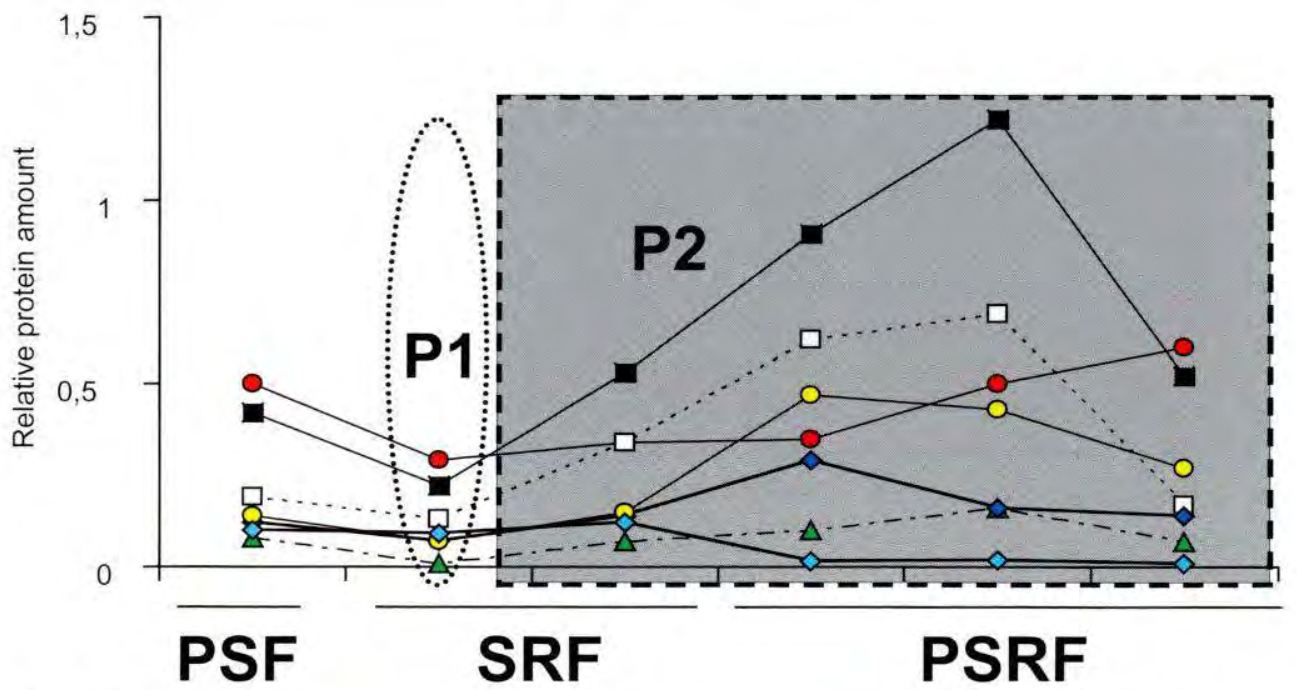

Fig. 2 Temporal relative amounts of seminal plasma proteins (O: PSP-I, $\mathbf{\square}:$ PSP-II, $\square$ : AQN-1, $\triangle: A Q N-3, \diamond: A W N-1,0: A W N-2, \diamond:$ inhibitor of acrosin/trypsin) in consecutive samples of the boar ejaculate (PSF: pre-sperm fraction, SRF: sperm-rich fraction, PSRF: post sperm-rich fraction (includes gel component)(modified from Rodriguez-Martinez et al. 2005).

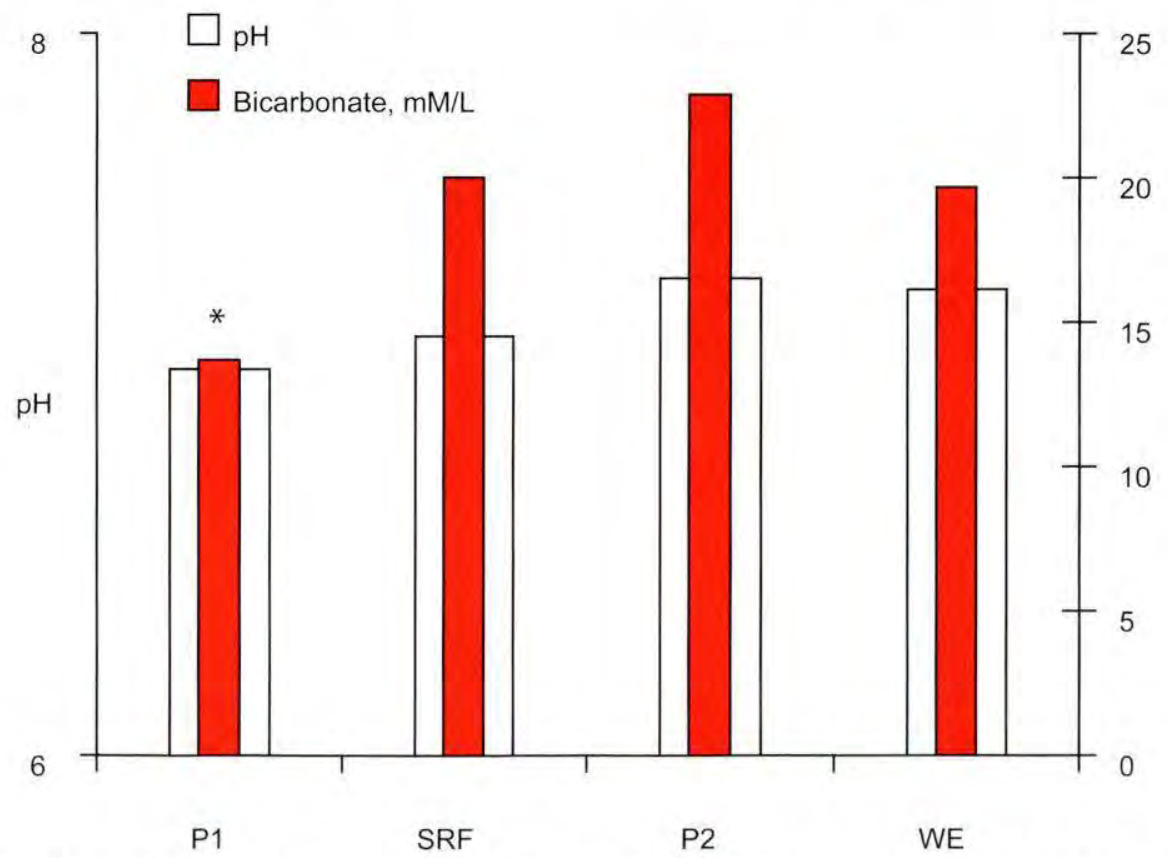

Fig. 3 Mean bicarbonate concentration $(\mathrm{mM} / \mathrm{L})$ and $\mathrm{pH}$ in different portions ( $\mathrm{P} 1$ and $\mathrm{P} 2)$, the sperm-rich fraction (SRF) of the ejaculate or the whole ejaculate (all fractions) of the boar ( $\mathrm{n}=$ 20 boars; P1: $1^{\text {st }} 10 \mathrm{ml}$ of the SRF, P2: the rest of the SRF and the PSRF, WE: whole ejaculate, including PSF, SRF and PSRF. *: P<0.05 (modified from Saravia et al., 2009b). 
The cation zinc, unusually abundant in boar SP (Massanyi et al. 2003) is also of utmost importance for sperm function, and it is secreted in the SP alongside sperm and fructose emission, as shown in Fig. 4. Zinc stabilises, among other functions, sperm chromatin in human (Björndahl \& Kvist 2003) and pigs (Kvist et al. 1987, Björndahl et al. 1990). In vivo, depletion of nuclear zinc by secretions decreases stability, being followed by a non-zinc, but disulphide-bridge dependent superestabilisation, which counteracts normal descondensation during fertilisation (Rodriguez-Martinez et al. 1990a). Such zinc-dependent stability can be challenged in vitro, by exposure to the detergent sodiumdodecylsulphate (SDS) and the zinc-chelating agent EDTA (a customary component of boar semen extenders, $6 \mathrm{mM}$ ) for $60 \mathrm{~min}$ at $60^{\circ} \mathrm{C}$, which decondenses the sperm nucleus (see Fig. 4). As depicted, boar spermatozoa ejaculated in the later expulsed sperm-bearing portions (PSRF, where zinc levels are significantly higher) become more superstabilised than those expelled in the first portions, particularly the P1, since they clearly diminished their capacity to decondense in vitro alongside ejaculation. However, the total SP-zinc concentration as such is not an indicator of the free zinc amount that equilibrates with the sperm zinc content. A concomitant increase in citrate, having three binding sites for zinc at slightly alkaline $\mathrm{pH}$, or presence of zinc-binding proteins could result in a zinc-chelating environment (Kvist et al. 1990).

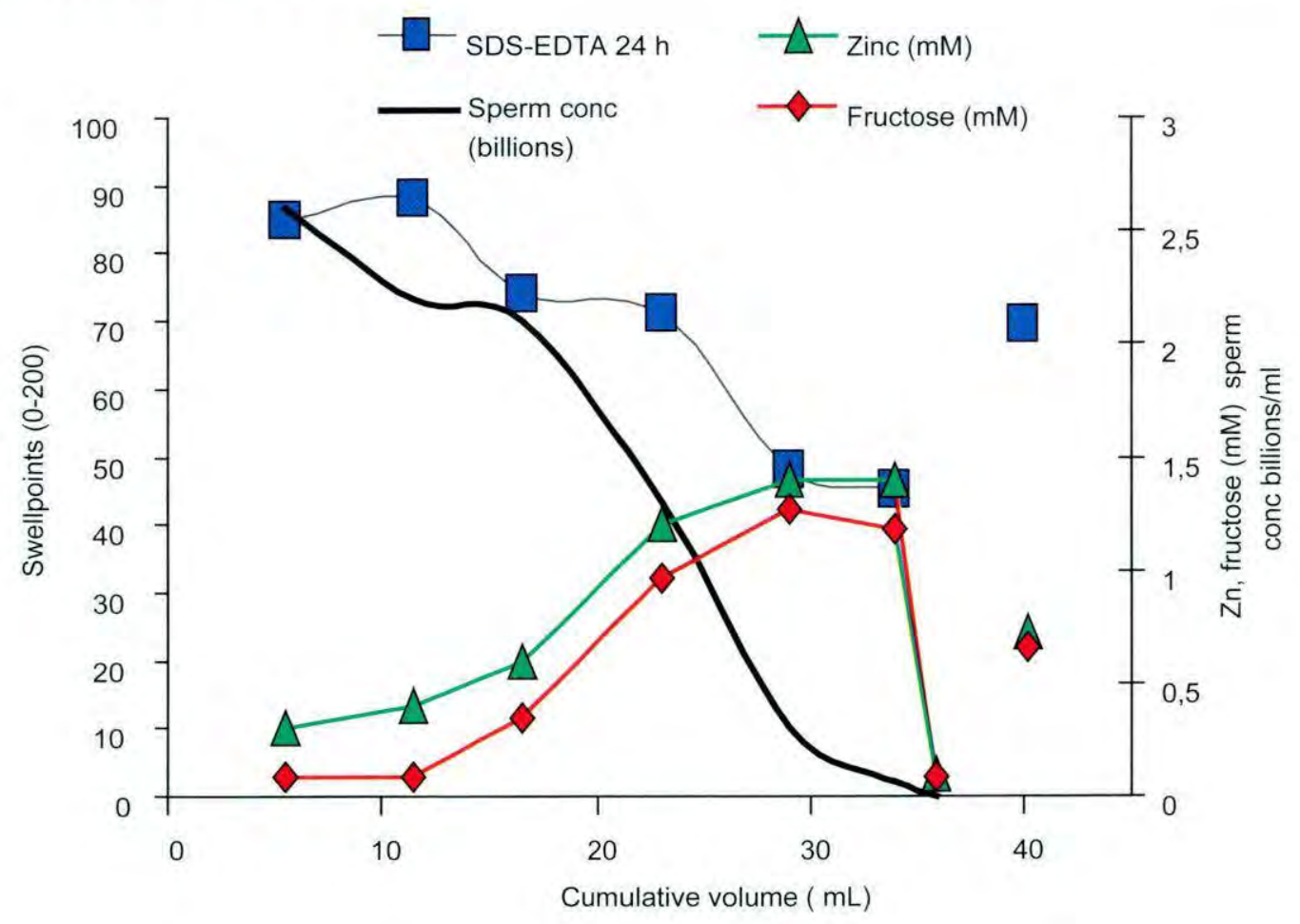

Fig. 4: Chromatin decondensation in vitro (of boar spermatozoa collected in $5 \mathrm{~mL}$ samples $(n=9)$ within the porcine sperm-rich fraction (SRF) and the post-sperm-rich fraction (PSRF) and an independently collected whole ejaculate (at 40$)$. Zinc ( $\mathrm{mM}$ ), fructose $(\mathrm{mM})$ and sperm numbers $\left(\times 10^{9} / \mathrm{ml}\right)$ are also depicted as markers. Decondensation was quantified as sperm nuclear swell-points* (i.e. the sum of $\%$ moderately decondensed sperm heads $x 1$ and the \% grossly decondensed sperm heads x 2, maximal swellpoints are 200) after exposure to SDS-EDTA at 24h. (Kvist et al. unpublished). 
The change from a zinc-dependent into a disulphide-dependent superstabilisation occurs upon storage of both cauda and ejaculated boar spermatozoa (Kvist et al., unpublished results) and enhanced by prior exposure to a zinc-chelating environment (Björndahl et al. 1990), as depicted in Fig. 5 for immature (from testis, rete testis, caput or corpus epididymides) or mature spermatozoa (from cauda epididymides, whole ejaculate and consecutive aliquots of the SRF [as A1-A4] and the PSRF [A5-A8]). Sperm chromatin decondensation in SDS-EDTA at 0 or $24 \mathrm{~h}$ post-collection was more readily seen in immature than in mature spermatozoa. While storage (up to $20 \mathrm{~d}$ ) promotes the disulphide-bridge dependent chromatin superstabilisation in immature spermatozoa, mature spermatozoa can sustain short storage ( $24 \mathrm{~h}$ ) without becoming superstabilised, provided they are not pre-exposed to zinc-chelating treatment (Björndahl et al. 1990). Zinc also seems to play a major role in maintaining the stability of the spermadhesin PSP-I/PSP-II heterodimer, an effect that can be reversed by EDTA or at acidic $\mathrm{pH}$, as found in the sperm reservoir (SR), i.e. a 1-2 cm segment of the utero-tubal junction (UTJ) and the adjacent isthmus of each oviduct (Rodríguez-Martínez et al. 2005), suggesting the female also regulates the extent of its action (Campanero-Rhodes et al. 2005).

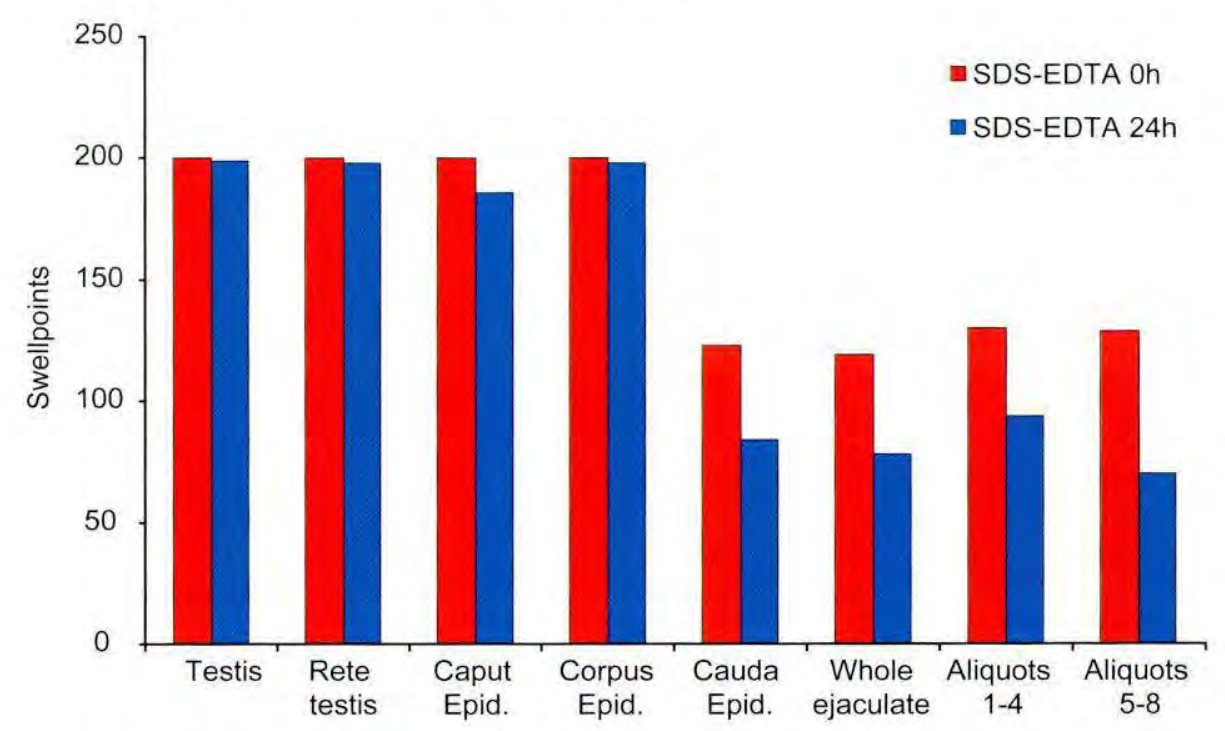

Fig. 5 Ability of the chromatin of boar spermatozoa, collected from various sources (testes, epididymides, whole ejaculate and consecutive aliquots of the SRF [Aliquots 1-4] and the PSRF [Aliquots 5-8]) to decondense in vitro (quantified as sperm nuclear swell-points*, i.e. the sum of $\%$ moderately decondensed sperm heads $x 1$ and the $\%$ grossly decondensed sperm heads $\times 2$, maximal swellpoints are 200) after exposure to SDS-EDTA at 0 or $24 \mathrm{~h}$ (Kvist et al. unpublished).

\section{Distribution of the ejaculated spermatozoa in the female}

During natural mating, the boar sequentially deposits the various fractions of the ejaculate in the cervical canal and elicits, by distending the uterine cavity, a stretching response from the myometrium. Both distention and SP-oestrogens, induce production/release of endometrial $\mathrm{PGF}_{2 \alpha}$ to, ultimately, provoke rhythmic, antiperistaltic (ad-ovarian) and peristaltic (ad-cervical) myometrial contractions. Antiperistalsis dominates the rapid phase of sperm transport through the 
female internal genital tract and transports - within minutes- a small subpopulation of spermatozoa towards the SR (Rodríguez-Martínez et al. 2005). Ad-cervical peristaltis effectively mixes the uterine sperm suspension since the cervical canal is plugged by the ejaculated gel fraction. At Al with gel-free liquid semen, these contractions cause a large retrograde flow (up to 35-40\% of the volume introduced, holding up to $20-25 \%$ of spermatozoa) within 30 min (Viring \& Einarsson 1981, Steverink et al. 1998).

When semen is deposited (via mating or $\mathrm{Al}$ ) pre-ovulation, enough spermatozoa $\left(10^{5}\right.$ to $10^{8}$ ) reach and colonise the functional tubal SR, to ensure successful fertilisation of all ovulated oocytes. Although this so-called $2^{\text {nd }}$ phase of sperm transport mainly occurs between 5 and 60 min from insemination, the SR replenishment can take longer, depending more on sperm numbers inseminated than on the number of following matings or Als (see review by Rodríguez-Martínez $2007 \mathrm{~b}$ and references therein). The tubal SR is immunologically-privileged (Bergqvist et al. 2005), where sperm viability and fertilising capacity are preserved (Rodríguez-Martínez et al. 2001, Tienthai et al. 2004) for the entire preovulatory period. From the SR, restricted sperm numbers $\left(10^{2}-10^{3}\right)$ are gradually, but apparently continuously released towards the presumed site of fertilisation at the ampullary-isthmic junction (AIJ), thus defining the $3^{\text {rd }}$ phase of sperm transport, particularly when ovulation is approaching or has occurred (Rodríguez-Martínez 2007b). Not all spermatozoa are trapped in the SR, and trans-oviductal passage occurs during the preovulatory period (Viring 1980) but it is most evident post-ovulation, when spermatozoa do not need a long SR-storage. In either case, sperm numbers are importantly reduced (to hundreds) at the AlJ, a fact that strongly contributes to the physiological ratio (1:1) between spermatozoa and oocytes during fertilisation in vivo (Hunter \& Rodríguez-Martínez 2004).

\section{Which spermatozoa colonise the sperm reservoir?}

Theoretically, anyone; provided they are potentially capable of interacting with the SR (Viring 1980). However, the sequentiality of the entry through the cervico-uterine lumen during mating has led to the hypothesis that the $1^{\text {st }}$ ejaculated sperm sub-population (in P1) is, by reaching first the SR, overrepresented there. P1- and P2- (last portion of the SRF and the PSRF) spermatozoa were collected from fertile boars. The P1-spermatozoa were loaded with the fluorophore Hoechst 33252, while P2 spermatozoa were kept unstained until conventional cervical Al of equal sperm numbers ( 10 $\times 10^{9}$ spermatozoa) per portion was performed ad modum $12 \mathrm{~h}$ after onset of oestrus in weaned sows; either mixing P1 and P2 aliquots (control, $n=5)$ in a single Al flask (90-mL dose), or testing (a) a sequential order (P1-P2, Treatment A, $n=5)$ with P1 $(10 \mathrm{~mL})$ inseminated first, immediately followed by deposition of $80 \mathrm{ml}$ of P2semen or (b) an inverse order (P2-P1, Treatment B, $n=5$ ). The sows were euthanized $\sim 3 \mathrm{~h}$ later and the SRs flushed to recover the spermatozoa, which were accounted for as stained and unstained. While the number of spermatozoa flushed from the SRs did not differ between groups nor between boars (NS, ranging 0.9 to $2 \times 10^{9}$ ), the proportion of stained P1-spermatozoa significantly $(P<0.05)$ differed between groups, but not between boars. The highest proportion of P1-spermatozoa in the SRs $(59.8 \pm 5.66 \%$, means \pm SEM) was found when a sequential order (P1-P2, Group TA) of insemination was issued (see Fig. 6). Reversing this order (Group TB, P2-P1) dramatically decreased the proportion to $15.6 \pm 2.1 \%$, much lower than when a mixed suspension (control) was inseminated at one time $(36.9 \pm 2.70 \%)$. The hypothesis tested proved valid; when spermatozoa were inseminated in the same order as ejaculated in vivo, they were overrepresented in the SR. It remains to be determined whether such proportionality is maintained at the site of fertilisation. 


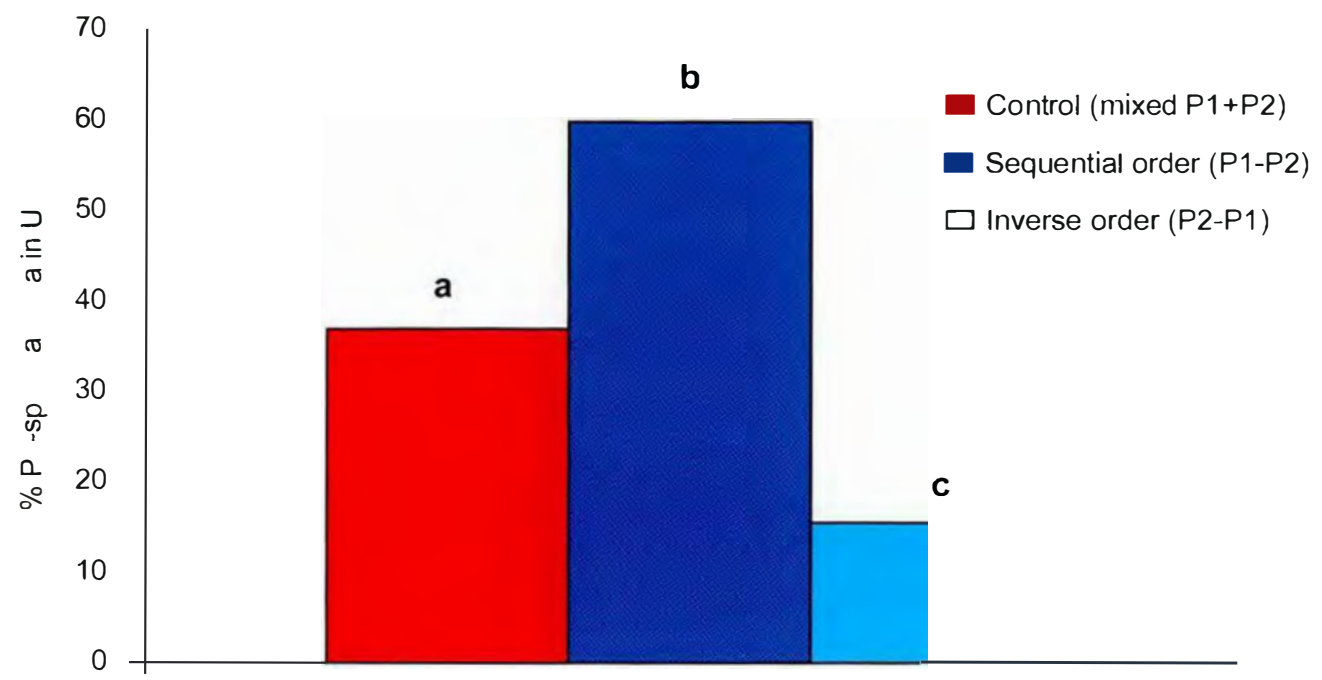

Fig. 6 Mean proportions of P1-spermatozoa present in the uterotubal junction (UTJ) of oestrous sows ( $n=15$, equally allotted) $3 \mathrm{~h}$ past-Al with a sequential order (P1-P2), an inverse order $(\mathrm{P} 2-\mathrm{P} 1)$ or a mixture $\left(\mathrm{P} 1+\mathrm{P} 2\right.$, control) of ejaculate portions $\left(\mathrm{P} 1: 1^{\text {st }} 10 \mathrm{ml}\right.$ of the SRF, P2: the rest of the SRF and the PSRF); a-c: different letters denote significant differences, $\mathrm{P}<0.05$ (Rodriguez-Martinez et al. unpublished).

\section{What happens with the spermatozoa that do not enter the sperm reservoir?}

While $\sim 40 \%$ of the volume of the Al-dose is lost rather quickly (within $30 \mathrm{~min}$ ) via vaginal reflux, this fluid only contains $\sim 22-25 \%$ of the inseminated spermatozoa. The remaining ones have either entered the SR "sanctuary" or are still in the uterine lumen. The uterine cavity is, $\sim 10$ min after Al, invaded by inflammatory polymorphonuclear granulocytes (PMNs) which migrate from the lamina propia (i.e., subjacent to the lining epithelium, where they accumulate after extravasation, presumably a result of the high levels of oestrogens that dominate prooestrus in pigs), through the lining epithelium (Lovell \& Getty 1968, Rodríguez-Martínez et al. 1990c), see Fig. 7a-c. Massive numbers luminal PMNs are first detected by $30 \mathrm{~min}$ (Lovell \& Getty 1968), to sustain entry for the following 2-3 h (Viring \& Einarsson 1981), surpassing the number of inseminated spermatozoa (Matthijs et al. 2003). This dramatic uterine PMNinflux is accompanied by accumulation of macrophages, granulocytes and lymphocytes in the endometrial stroma and, to a lesser extent, into the base of the lining epithelium (RodríguezMartínez et al. 1990c, Bischof et al. 1994, Kaeoket et al. 2003, Robertson 2007); a picture not seen in the oviduct, except for the mesothelial-covered infundibulum (Jiwakanon et al. 2006) and for the presence of lymphocyte-like cells in the base of the SR and the adjoining isthmus (Rodríguez-Martínez et al. 1990c). The resulting mass of leukocytes and sperm/SP-debris are, during this hourly period, eliminated from the lumen by continuous vaginal discharge but also by epithelial phagocytosis (Rodríguez-Martínez et al. 1990c) so that a new inseminate can enter a cleansed uterine lumen, free from redundant spermatozoa or semen-associated microorganisms. The lumen must, moreover, be ready to host and nurture the semi-allogeneic early embryos when they enter the uterus by $48 \mathrm{~h}$ after ovulation. 

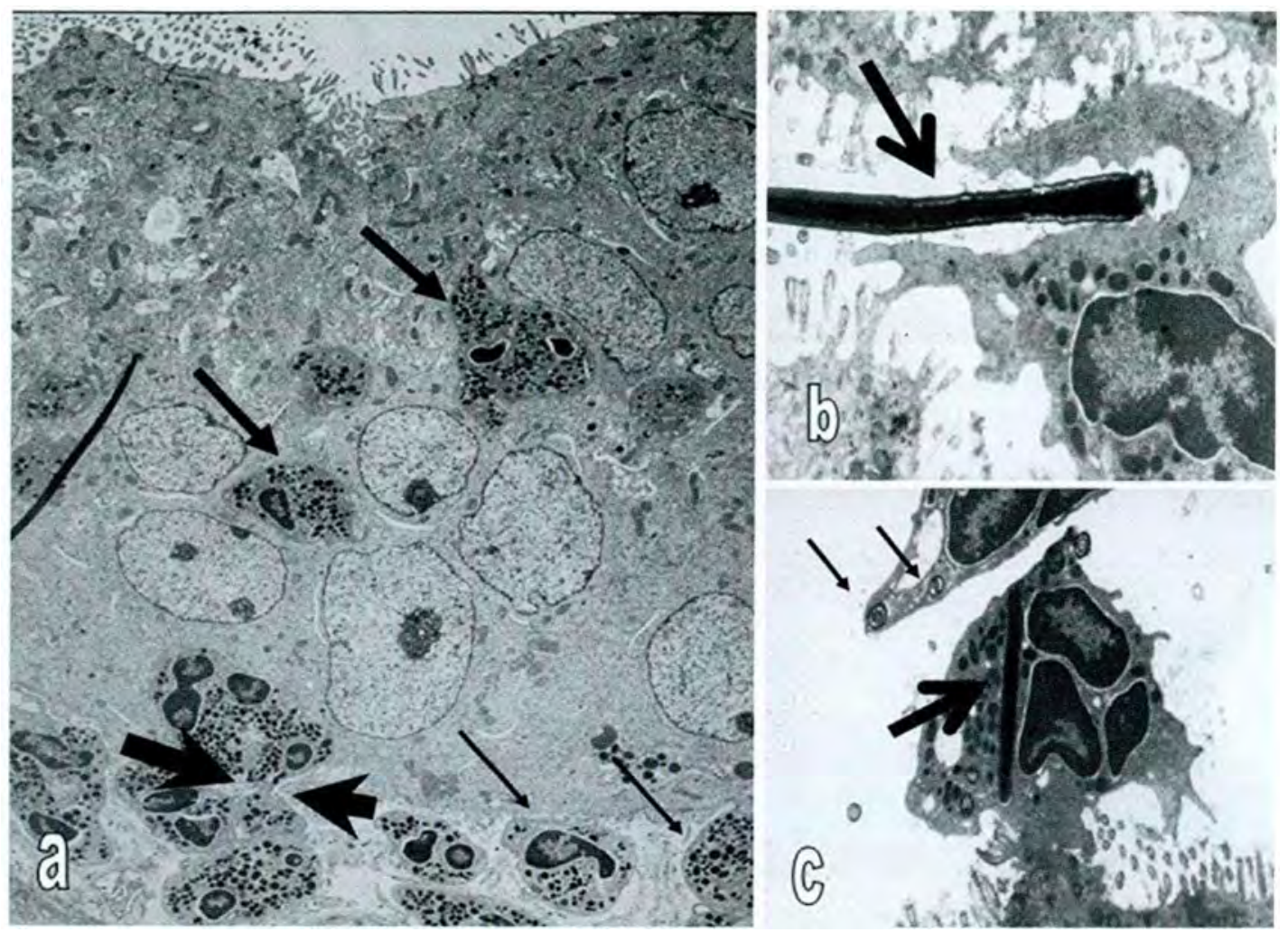

Fig. 7a-c: Entry of polymorphonuclear leukocytes (PMNs) into the uterine lining epithelium (a) and lumen $(b, c)$ of oestrous sows, following Al of neat semen. The TEM-micrographs show the migration of PMNs from the lamina propria (a, thin arrows), through the basal membrane (a, between thick arrows) to the lining epithelium (a, medium-arrows) and the lumen $(b, c)$ where they phagocytose individual spermatozoa (large arrows: sperm heads in b and c, small arrows: sperm tails in c)(micrographs H Ekwall, SLU).

\section{Does the seminal plasma modulate the genital immunology of the female?}

Or do the "per natura-antigenic" spermatozoa also play a role? While sows do not show changes in cellular immune reactivity after Al (Veselsky et al. 1981), gilts exposed to sperm and/or seminal antigens increased litter size in a following fertile mating (Murray \& Grifo 1983, Flowers \& Esbenshade 1993). Al with washed boar spermatozoa caused a greater influx of PMNs into the uterine cavity of gilts compared to SP or whole semen (Rozeboom et al. 1998, 1999), suggesting their chemotactic character (Rozeboom et al. 2001a). In contrast, Al of sperm-free SP increased by 5.4-fold the number of PMNs infiltrating the porcine uterine lumen (O'Leary et al. 2004).

Most data now suggest that the SP ensures reproductive success by promoting the survival of some spermatozoa, and conditioning the female immune response to tolerate paternal antigens. SP initiates - by interaction with the luminal epithelium- a cascade of downstream immunological effects, including the advancement of ovulation (Waberski et al. 2006), the production of progesterone $\left(\mathrm{O}^{\prime}\right.$ 'Leary et al. 2006) and other defence/immune responses. SP upregulates MHC class II and interleukin-2 (IL-2) receptor expression (Bischof et al. 1994), induces the transitory expression of pro-inflammatory (PMN-attractants) soluble cytokines (as 
IL-1) and cyclo-oxygenase-2 (O'Leary et al. 2004) and the expression of interleukin-6 (IL-6), granulocyte-macrophage colony-stimulating factor (GM-CSF), and the monocyte attractant protein-1 (MCP-1) which, towards early pregnancy, leads to a transition of leukocyte phenotypes, PMNs being replaced by macrophages and dendritic cells (Robertson 2007). Boar SP also contains high levels of the immunosuppressive transforming growth factor- $\beta$ (TGF- $\beta$, Robertson et al. 2002), a very potent, multifunctional cytokine group which, in the pig, regulates T-cell differentiation to reach a state of functional, adaptative immune tolerance to male antigens by the female (O'Leary et al. 2004, Robertson 2007). This would explain why priming to seminal antigens improves fertility in pigs in later oestrous events (Murray \& Grifo 1983, Flowers \& Esbenshade 1993, Rozeboom et al. 2000). Moreover, inter-boar differences in cytokine SPcontent might lead to different adaptation levels by the females (Robertson 2007), thus suggesting the SP-induction of maternal tolerance might relate to the differences in embryo survival often observed among sires (e.g. innate fertility).

SP-infusion studies have, however, lead to -at first sight- paradoxical results, probably owing to differences in animal categories, methods and experimental design used. For instance, SP either induced (Bischof et al. 1994, O Leary et al. 2004, Rodríguez-Martínez et al. 2005) or attenuated (Veselsky et al. 1991, Rozeboom et al. 1999, 2001b, Taylor et al. 2008, 2009) the inflammatory response of the pig endometrium during mating or AI. It is possible that we are simply facing several steps, firstly a transitory inflammatory response initiated by the SP and a secondary recruitment of antigen-presenting cells (macrophages and dendritic cells), prerequisite for the generation of paternal antigen-specific T-cells (Schuberth et al. 2008).

SP-spermadhesins such as the PSP-I/PSP-II have shown capacity to bind to (Yang et al. 1998), and to enhance pig lymphocyte proliferation (Leshin et al. 1998). We tested, therefore, whether pig HBPs and PSPs, isolated from the SP of SRF samples collected from mature, fertile boars (Calvete et al. 1996, Rodriguez-Martinez et al. 2005) could recruit PMNs and different lymphocyte subsets into the lining epithelium of the pig uterus in vivo. Consecutive biopsies were taken (2-120 min) under narcosis and treated histologically and by immunohistochemistry (IHC) using mAbs against CD2, CD4 or CD8 lymphocyte subsets. Compared to controls (saline-infused uteri), exposure to the PSP-I/PSP-II heterodimer significantly $(\mathrm{P}<0.05)$ induced the migration of PMNs ( $\log _{10}$ ) to the surface epithelium, within $10 \mathrm{~min}$ of infusion (Fig. 8), a recruitment that was sustained over the experimental period, becoming 5 -fold by 30 min and 7 -fold higher from 60 min onwards $(P<0.001)$. PMNs were detected in the uterine lumen by $30 \mathrm{~min}$ and thereafter. The infusion of a similar dose of HBPs had no significant effect (NS). Regarding the IHC (Fig. 9), saline infusion did not significantly increase the number of CD2, CD4 nor CD8 positive $(+)$ cells in the epithelium or the lamina propria over time (NS). CD2+ cell numbers were only significantly increased ( 4 to 7 -fold from 10 min onwards) by infusion of PSP while no significant effect of any treatment was seen on CD4 + cells. CD $8+$ cell numbers increased significantly (3-fold) only after 60 min of the infusion of PSP. A 1-2 fold higher amount of CD8 + cells was seen during the entire period following the infusion of HBPs (NS). In sum, the heterodimer PSP-I/PSP-II induced an increase in the numbers of some uterine lymphocytes (such as CD2 + [Tk, NK, cytokine-rearing cluster] and CD8 + [cytolytic] cells, Gerner et al. 2009 ) in vivo. Numbers increased earlier for CD2 + (from 10 min onwards) than for CD $8+$ (60 $\mathrm{min})$, suggesting that this immunostimulatory effect could be of primary nature. However, albeit being done in vivo, and registering changes over time (2-120 min), this experiment was done under narcosis, on few animals and testing single CD-subsets rather than combinations, which would have provided a more accurate quantification of the processes. On the other hand, PSP-I/PSP-II was confirmed as leukocyte chemoattractant in pigs, confirming previous in vitro (Leshin et al. 1998) and in vivo studies (Rodriguez-Martinez et al. 2005). Al of SP-PSPs in conscious oestrus sows, at doses 5 -fold lower $(3 \mathrm{mg} / \mathrm{ml}, 100-\mathrm{ml}$ dose) than those present in the 
boar ejaculate, led to a substantial (6-fold higher than in controls) recruitment of PMNs to the uterine cavity $(35.4 \pm 12.56$ vs $5.83 \pm 4.62$ million $\mathrm{PMN} / \mathrm{ml}$, mean $\pm \mathrm{SD}, \mathrm{P}<0.001)$. It remains to study, however, whether any portion of the ejaculate can induce this PMN entry.

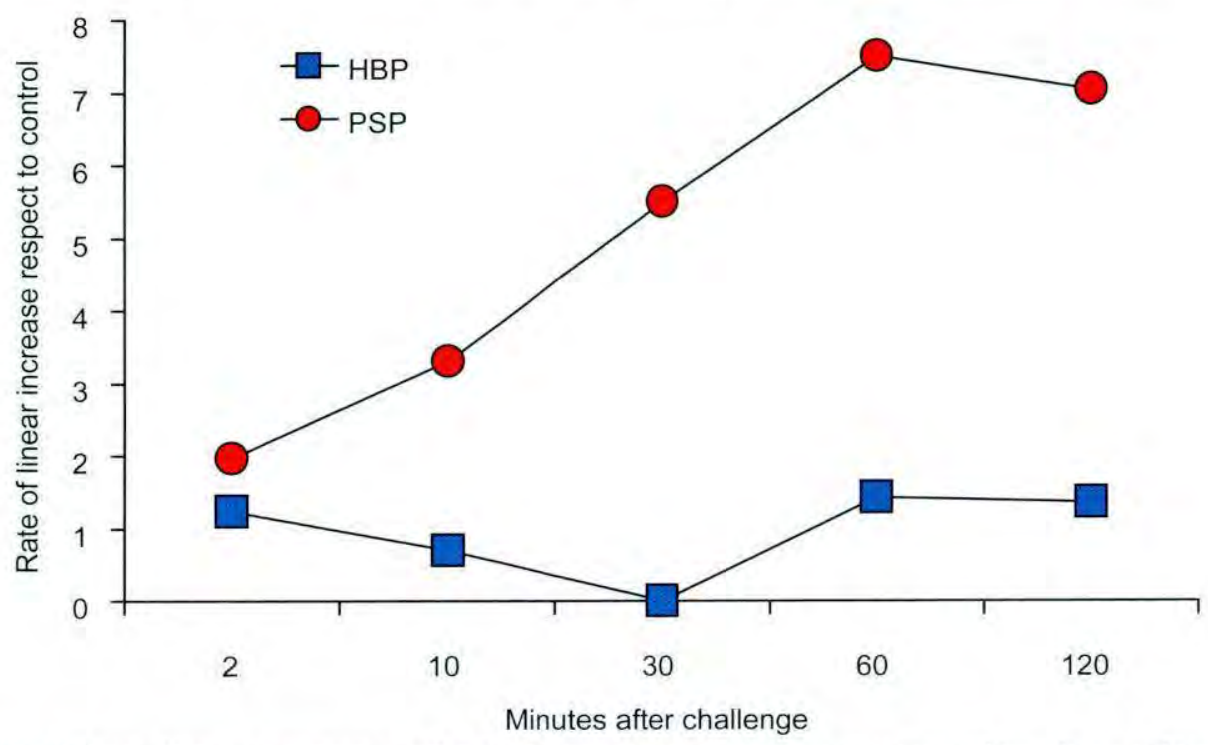

Fig. 8 Rate of linear increase rate for PMN recruitment (compared to control i.e. sham, saline infused uterine horn) to the uterine surface epithelium in oestrous sows $(n=6)$ at various times (2-120 min) after intrauterine infusion of porcine SP-HBP (HBP) or SP-PSPI/PSP-II (PSP) spermadhesins ( $3 \mathrm{mg} / \mathrm{ml}, 100-\mathrm{mL}$ dose). The identity and purity of the protein preparations were assessed by $\mathrm{N}$-terminal sequence analysis and Matrix-Assisted Laser Desorption/ Ionization Time-of-Flight (MALDI-TOF) mass spectrometry while amino acid analysis was used to quantify the amount of either protein (which averaged $15 \mathrm{mg} / \mathrm{ml}$ ). Sows were, under narcosis, unilaterally infused with spermadhesins, respectively saline and endometria removed for biopsy at various intervals. The tissues were fixed ( $2 \%$ paraformaldehyde) and processed for histology and manual counting of PMNs at x400 using an ocular reticulum on coded slides. The relative number of cells $(\log 10)$ was quantified in treatment vs control tissues at each time interval (Rodriguez-Martinez et al., unpublished).

\section{Why are there sperm subpopulations in the boar ejaculate?}

Many studies, including our own, have described the presence of sperm subpopulations in the boar ejaculate either by chromatin stability, morphology, motility or membrane resistance variables (Rodriguez-Martinez et al. 1987, Cremades et al. 2005, Peña et al. 2005, Saravia et al. $2007 \mathrm{~b}$ and references therein, Druart et al. 2009) or even by fertilizing capacity in vitro (Xu et al. 1996, 1998; Zhu et al. 2000). These sperm subpopulations are apparently distributed either along the entire ejaculate, or within major fractions, such as the SRF. We therefore focused, from 2001, on portions of the SRF and PSRF, the so-named P1 and P2, seeking for differences in resilience between spermatozoa fortuitously ejaculated in one of these portions. Spermatozoa bathing in P1 cope better with different handling, such as storage at room temperature, cooling, or freezing-thawing, than P2-spermatozoa (Sellés et al. 2001, Peña et al. 2006, Saravia et al. 2007a, 2009a and references therein). Obviously, these differences would not be specifically allotted to differences among spermatozoa, since spermatozoa collected in the entire SRF (as praxis) are able to sustain handling as well. We have now established that it is the SP from 


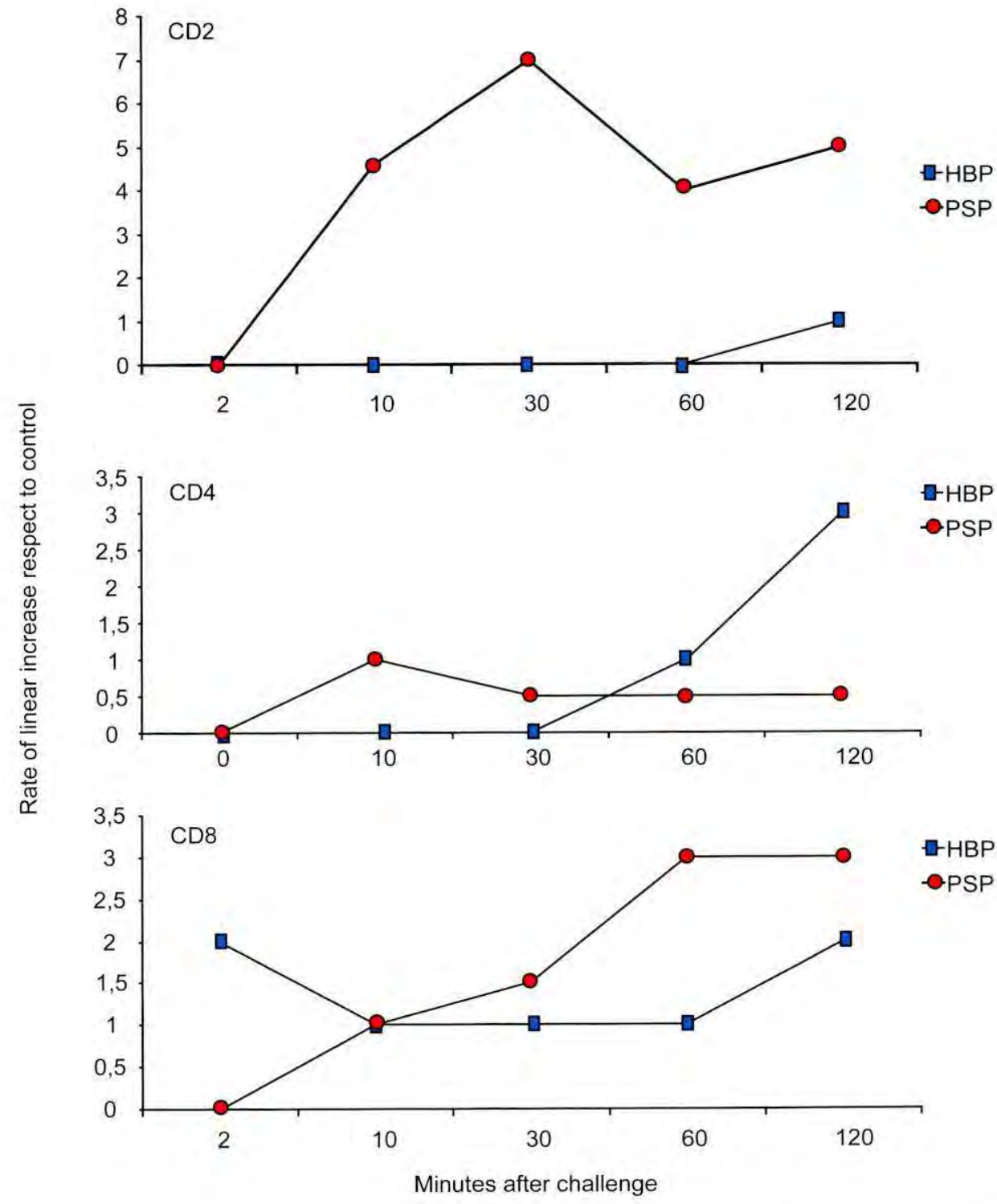

Fig. 9 Rate of linear increase rate for lymphocyte subsets (CD2, CD4 and CD8) recruitment (compared to control) to the uterine surface epithelium in oestrous sows $(n=6)(2-120 \mathrm{~min})$ after intrauterine infusion of porcine SP-HBP (HBP) or SP-PSPI/PSP-II (PSP) spermadhesins (3 $\mathrm{mg} / \mathrm{mL}, 100-\mathrm{ml}$ dose). For description of the identity and purity of the protein preparations and general procedures see Fig. 8. Immunohistochemistry (IHC) using microwave-effected antigen retrieval was done with a standard avitin-biotin immunoperoxidase technique and primary mouse mAbs (VRMD, Pullman, WA, USA). Counting of IHC-marked T-cells in the tissue for biopsy was done at $\times 400$ using an ocular reticle (tissue area: $0.0625 \mathrm{~mm}$ ), on coded slides. Particular attention was taken to the lining epithelium and the subjacent lamina propia. The relative number of cells $\left(\log ^{10}\right)$ was quantified in treatment tissues against control tissues, at each time interval (Rodriguez-Martinez et al., unpublished). 
these ejaculate portions (P1-SP or P2-SP) that differently influences sperm kinematics of those fortuitously P1- or P2-contained spermatozoa from individual boars, primarily or secondarily exposed (i.e. following cleansing and re-exposure) to pooled P1-SP or P2-SP from the same males during $60 \mathrm{~min}$. Spermatozoa were subjected to controlled cooling and thawing in MiniFlatPacks ${ }^{\mathrm{TM}}$ (MFPs) and examined for motility (CASA) at selected stages of processing. A higher proportion of P1 spermatozoa than of P2 spermatozoa incubated in their native SP portion were motile from collection to post-thawing. When P1-spermatozoa were cleansed from their original SP and re-exposed to pooled P2-SP, sperm kinematics deteriorated from extension to thawing. By contrast, cleansed P2 spermatozoa increased motility to P1 levels, especially after thawing (Fig. 10) when re-exposed to pooled P1-SP. This influence of SP on sperm kinematics was not sire-dependent and presumably related to different concentrations or either SP proteins or other factors in the different SP-portions (Rodríguez-Martínez et al. 2008, Saravia et al. 2009a).

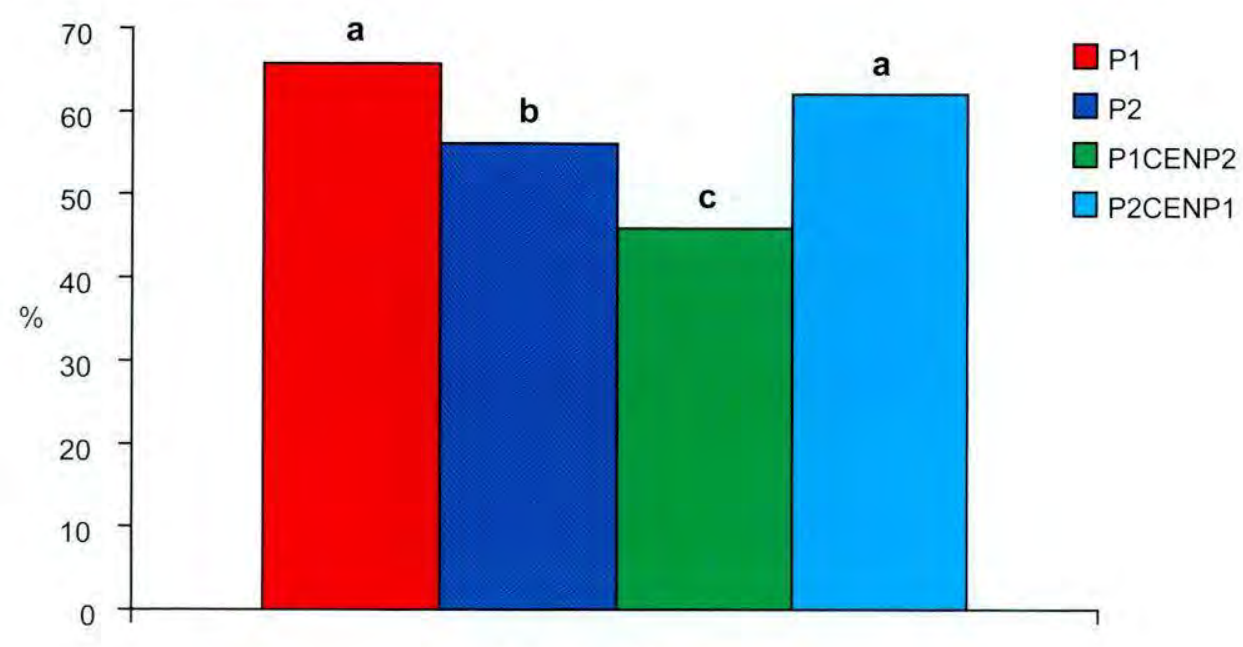

Treatments

Fig. 10 Cryosurvival (\% motility post-thawing) of boar spermatozoa either held in their "native" seminal plasma (P1-SP or P2-SP) for $60 \mathrm{~min}$ at room temperature or cleansed by centrifugation and incubated for 60 min t room temperature in the "other SP", as P1CENSP2 (spermatozoa from P1 cleansed and exposed to SP from P2) or P2CENSP1 (spermatozoa from P2 cleansed by centrifugation and exposed to SP from P1) ( $\mathrm{n}=25 ; \mathrm{P} 1: 1^{\text {st }} 10 \mathrm{ml}$ of the SRF, P2: the rest of the SRF and the PSRF), a-c: different letters denote significant differences, $P<0.05$ (modified from Saravia et al. 2009a).

What are the differences between the P1-SP and P2-SP? Several, many of these already enumerated, such as they differ in zinc and bicarbonate amounts, the latter being 2-fold lower in P1-SP than in P2-SP (Fig. 3). In relation to this, the $\mathrm{pH}$ of P1-SP was $3 \mathrm{pH}$ units lower than that in P2-SP. The ion bicarbonate plays important roles in sperm physiology, both by maintaining intracellular $\mathrm{pH}(\mathrm{ipH})$ and the homeostasis of the cell, and by modulating sperm motility and membrane stability through its effects on the sperm adenylyl cyclase (Henning et al. 2008). It is responsible for the initiation of motility at ejaculation (Rodríguez-Martínez 1991), and it is also considered the main effector of changes within the lipid bilayer of the sperm plasma membrane that are associated with sperm capacitation in vivo in the pig (Tienthai et al., 2004). A lower concentration of bicarbonate (and lower $\mathrm{pH}$ ) in P1-SP would modulate the ipH of the surrounding spermatozoa and thus its kinematics (Gatti et al. 1993, Saravia et al. 2009a). 
P1-SP and P2-SP significantly differ also in their contents of total protein (the P1-SP having only $17-18 \%$ of the total, Rodriguez-Martinez et al. 2005). In addition, the P1-SP and P2-SP have clearly distinct protein profiles, the P2-SP having the highest concentration of spermadhesins, in particular glycoforms of PSP-I/PSP-Il heterodimer of high mass (Rodriguez-Martinez et al. 2005). Using one- and two-dimensional SDS-PACE electrophoresis to separate proteins in P1 and $P 2$, followed by in-gel enzymatic digestion, mass fingerprinting and collision-induced dissociation tandem mass spectrometry (CID-MS/MS) for peptide sequencing, we have recently confirmed that the P2-SP mostly contained spermadhesins, while the P1-SP contained, besides PSP-I, actin and proteins of the Lipocalin family, namely the lipocalin-type Prostaglandin D-synthase (L-PGD-S), Epididymal Secretory Protein-1 (ESP-1) and Lipocalin (Table 1)(Calvete et al. unpublished). Lipocalins are multifunctional proteins, involved in retinol transport, pheromone-binding and transport and prostaglandin synthesis (Flower 1996, Marchese et al. 1998). As major epididymal proteins secreted in the caput segment, both EPS-1 and L-PGD-S are relevant for sperm maturation (Fouchecourt et al. 2002, Leone et al. 2002) and sperm quality (Chen et al. 2007). L-PGD-S, primarily involved in transporting retinoids and other lipophilic ligands, binds to the sperm apical ridge being strongly related to sire fertility, including pigs (Gerena et al. 1998, Fouchecourt et al. 2002, Flowers 1995).

Table 1. Identification of protein spois in boar seminal plasma portions P1 (first $10 \mathrm{~mL}$ of the SRP) and P2 (the rest of the SRF and the PSRF), separated by one (1D) and two (2D) dimensional SDS-PAGE electrophoresis followed by in-gel enzymatic digestion, mass fingerprinting and collision-induced dissociation tandem mass spectrometry (CID-MS/MS) to sequence selected peptide ions (Calvete ef al., unpublished).

\begin{tabular}{|c|c|c|c|c|c|c|c|}
\hline \multicolumn{2}{|c|}{$\begin{array}{c}\text { 1D } \\
\text { SDS-PAGE }\end{array}$} & \multicolumn{2}{|c|}{$\begin{array}{c}2 D \\
\text { SDS-Page }\end{array}$} & \multicolumn{2}{|c|}{ Peptide ion } & \multirow[t]{3}{*}{ MS/MS-derived sequence } & \multirow[t]{3}{*}{ Protein } \\
\hline & \multicolumn{3}{|c|}{ Ejaculate portion } & $\mathrm{m} / \mathrm{z}$ & $z$ & & \\
\hline P1 & P2 & $P_{1}$ & P2 & & & & \\
\hline 1 & & 1 & & 488.4 & 2 & AGFAGDDAPR & Actin [Q6QAQ1] \\
\hline 2 & & & & 675.3 & 2 & GFTEDGIVFLPR & $\begin{array}{l}\text { Lipocalin-type Prostaglandin } \\
\text { D synthase [Q765P8] }\end{array}$ \\
\hline 3 & & & & 569.3 & 2 & (214.2)TVVATDYR & Unknown \\
\hline \multirow[t]{7}{*}{4} & & & & 744.7 & 2 & (258.1)CTYFCDXPR & Unknown \\
\hline & & 2 & & 584.6 & 2 & GTPXANGDXAXK & Lipocalin [ XP_001917526] \\
\hline & & 3,4 & & 508.4 & 2 & SGINCPIQK & $\begin{array}{l}\text { Epididymal Secretory Protein } \\
1 \text { [097763] }\end{array}$ \\
\hline & & $5-8$ & $1-7$ & 524.3 & 2 & LDYHACGGR & PSP-I [P35495] \\
\hline & & & 8 & 528.3 & 2 & CSDDCGGFLK & AQN-3 [P24020] \\
\hline & & & 9 & 508.8 & 2 & INGPDECGR & PSP-II [P35496] \\
\hline & & & 10,11 & 925.8 & 3 & ASFHIYYYADPEGPLPFPYFER & AWN [P26776] \\
\hline
\end{tabular}

Is there any relation between ejaculate characteristics and fertility?

The obvious answer would be yes. However, to determine which characteristic is most relevant and, particularly, if it could be measured in vitro remains elusive (Popwell \& Flowers 2004) since we are unable to relate results of sperm function to the fertility of pigs, which is not binary as in bovine, but combines pregnancy/farrowing and prolificacy (litter size). Moreover, by inseminating excessive sperm numbers, we mask the relations between measurements of sperm attributes (measured singly [motility, membrane integrity etc] or collectively [ZP-binding, IVF etc], Rodriguez-Martinez 2007a, Foxcroft et al. 2008).

As already enumerated, the SP plays major roles, at the level of the spermatozoa they cover and interact with, and for the signalling they excert towards the female genital tract, which has 
consequences beyond our current understanding. Seminal antigens have proven beneficial for fertility improvement in vivo, with substantial variation among boars (Murray \& Grifo 1983, Flowers \& Esbenshade 1993, Rozeboom et al. 2000), suggesting that the SP of a boar differs somehow from that of another boar. A logical immediate difference is a variation in the type and the relative amounts of SP-proteins, of which some have been correlated to in vivo fertility and thus collectively named "fertility-asociated", such as the L-PGD-S (Flowers 1995, 1997, review by Foxcroft et al. 2008), clearly present in the P1-SP (Table 1). However, when these proteins have been tested in vivo or in vitro, results have varied, once more probably caused by the excessive sperm numbers used. Another major question remains; which is the mode of action of these SP-proteins? One tempting hypothesis has been already launched (Robertson 2007), where established differences in SP cytokine contents would lead to different degrees of maternal tolerance by the female and thus attain differences in embryo survival, leading to variation in fertility and, particularly, prolificacy between boars. It is hoped that this line of research will be followed.

\section{Can we use this knowledge for boar semen processing or porcine Al?}

Porcine SP from the SRF influences sperm physiology (reviewed by Rodríguez-Martínez et al. 2008). On the other hand, SP from solely the PSRF, with a higher amount of bulbourethral gland fluid reduced semen fertility (Iwamoto et al. 1992), presumably by the relatively increasing presence of AQN-3 in this portion (Iwamoto et al. 1995, see Table 1). Removal of SP (by extension in a buffer and further centrifugation/re-extension) is, therefore, customary during conventional cryopreservation of boar semen. However, SP-exposure is not solely negative. Addition of bulk SP to boar semen was initially considered to ameliorate the effects of sperm processing (from extension to sex-sorting) on sperm survival and the fertility after $\mathrm{Al}$, mostly using empirical approaches (review by Caballero et al. 2008 and references therein). Addition of bulk SP $(12.5 \% \mathrm{v} / \mathrm{v})$ to semen for $\mathrm{Al}$ attenuated endometrial post-breeding reactions in vitro (Rozeboom et al. 2001b, Taylor et al. 2009) and in vivo (Rozeboom et al. 1999, 2000), but individuals still reacted when foreign proteins (such as BSA) were present (Taylor et al. 2009). Bulk SP-addition $(-10 \%)$ of bulk SP increased sperm longevity post-thaw (Einarsson \& Viring 1973), apparently by preserving membrane stability (Vadnais et al. 2005), as it occurs after flow cytometry for sex-sorting (review by de Graaf et al. 2008). Al-fertility could be improved adding 25-30\% v/v of SP (Crabo \& Einarsson 1971, Larsson \& Einarsson 1976) but not when $\sim 10 \%$ SP was added (Abad et al. 2007, Kirkwood et al. 2008). Positive effects (motility, viability and in vitro fertilising capacity) of adding exogenous SP (5\% v/v) to semen during cooling were only seen when the supplement SP was derived from boars judged to have good semen freezability, irrespective of the total SP protein amount or profile (Hernández et al. 2007). This evident variation in results when using SP-supplementation is not surprising, since SP-addition was between $5 \%$ and $100 \% \mathrm{v} / \mathrm{v}$, the SP used was either from the whole ejaculate (all fractions), different fractions, or solely from the SRF, from individual boars or from pooled sources, disregarding the large variability in SP-composition seen among sires, owing to age, breed and most likely having a genetic background (Roca et al. 2006). Exposure of highlyextended spermatozoa to low doses $(1.5 \mathrm{mg} / \mathrm{ml})$ of well identified SP-proteins gave different results. HBP-spermadhesins, which play major roles during sperm transport and fertilisation (Calvete et al. 1997, Rodriguez-Martínez et al. 1998), were not beneficial for sperm viability in vitro (Centurión et al. 2003). PSPs, on the other hand, provided substantial protection and maintained fertilising capacity (Caballero et al. 2004, 2006, 2008 and references therein). However, such benefits of PSPs could not be shown when handling high sperm concentrations 
(as praxis when handling boar semen for $\mathrm{Al}$ ) nor during cryopreservation (Hernández et al. 2007), probably because the spermatozoa had already been in contact with higher amounts of the SRF-SP after collection.

SRF-boar spermatozoa incubated at room temperature in their own SP became more resistant to cold shock (Pursel et al. 1973) and had, when pre-incubated for 3-20 h, higher post-thaw survival and fertilising capacity (Eriksson et al. 2001). Such incubation post-ejaculation with their surrounding SP is, therefore, nowadays customary in our laboratory, during the temperature decrease from $35-30^{\circ} \mathrm{C}$ to room temperature, before first extension with BTS for $30-60 \mathrm{~min}$ (Saravia et al. 2007a, 2009a).

Removal of the vesicular glands did not affect either the freezability or the fertility of frozenthawed boar spermatozoa (Moore \& Hibbitt 1977), possibly by abolishing the documented induction of chromatin superstabilisation (Kvist et al. 1987), or the reduction of sperm binding to the oviduct (Summers \& Pena 2008) caused by the vesicular gland fluid. Considering this would place the P1-spermatozoa in advantage, we recently attempted to simplify the customary freezing protocol for boar semen. We used solely P1-spermatozoa, holding them in their "native" SP for $30 \mathrm{~min}$, extended with Lactose-EggYolk (LEY) before cooling to $+5^{\circ} \mathrm{C}$ within $1.5 \mathrm{~h}$, prior to being mixed with LEY + glycerol and orvus-es-paste (LEYGO), packed into MFP, and customarily frozen. The entire procedure, here named "simplified freezing (SF)" lasted $3.5 \mathrm{~h}$ compared to the "conventional freezing (CF)" that was used as control procedure, which lasted $8 \mathrm{~h}$ (Saravia 2008, Saravia et al. 2009b). As controls, spermatozoa from the SRF were compared to P1-spermatozoa. The P1-SF-processed semen showed similar proportions of sperm motility (and kinematics), plasma membrane and acrosome intactness post-thaw, to the SRF-semen customarily frozen (SRF-CF). Mean post-thaw sperm motility ranged from $56 \%$ to $69 \%$, the highest percentages being among the P1-SF. Interestingly, there was barely any variation between sires or within-sire for P1-derived variables, in contrast to SRF, independent of the handling method (CF or SF). The reason behind a maintained P1-sperm survival after this shorter freezing process is yet unknown, but the particular milieu of the P1-SP (protein levels and types, lower bicarbonate, zinc and fructose levels etc), together with the use of the cryobiologically well-suited MFP are highly relevant. We are now awaiting for intended fertility trials to determine whether the fertilizing capacity of the processed semen was also preserved by the $\mathrm{P} 1-\mathrm{SP}$ as most in vitro results indicate.

\section{Acknowledgments}

The excellent technical support of the late Ȧsa Jansson is posthumously acknowledged. Funding has been provided by FORMAS and the Swedish Farmers' Foundation for Agricultural Research (SLF), Stockholm, Sweden; GERM (04543/07), MCN (AGL 2008-04127) and Séneca Foundation, Murcia; and BFU2007-61563, MCl, Madrid, Spain.

\section{References}

Abad M, Garcia JC, Sprecher DJ, Cassar G, Friendship RM, Buhr MM \& Kirkwood RN 2007 Effect of insemination-ovulation interval and addition of seminal plasma on sow fertility to insemination of cryopreserved sperm. Reproduction in Domestic Animals 42 418-422.

Bergquist AS, Killian G, Erikson D, Hoshino Y, Báge R, Sato E \& Rodríguez-Martínez H 2005 Detection of Fas ligand in the Bovine Oviduct. Animal Reproduction Science $8671-88$.

Bischof RJ, Lee CS, Brandon MR \& Meeusen E 1994 Inflammary response in the pig uterus induced by seminal plasma. Journal of Reproductive Immunology 26 131-146.

Björndahl L \& Kvist U 2003 Sequence of ejaculation affects the spermatozoon as a carrier and its message. 
Reproductive Biomedicine Online 7 440-448.

Björndahl, L, Kvist U, Rodriguez H \& Plöen L 1990 Cysteine interacts with a zinc dependent chromatin stability in epididymal boar spermatozoa. In: Fertilization in Mammals pp 416 Eds BD Bavister, J Cummins \& ERS Roldan, Serono Symposium, Norivell, MA,USA.

Caballero 1, Vazquez IM, Centurion F, RodriguezMartinez H, Parrilla I, Roca J, Cuello C \& Martinez E 2004 Comparative effects of autologous and homologous seminal plasma on the viability of largely extended boar spermatozoa. Reproduction in Domestic Animals 39 370-375.

Caballero I, Vazquez IM, Garcia EM, Parrilla I, Roca I, Calvete JJ, Sanz L \& Martinez EA 2008 Major proteins of boar seminal plasma as a tool for biotechnological preservation of spermatozoa. Theriogenology 70 1352-1355.

Caballero 1, Vazquez JM, García EM, Roca J, Martínez EA, Calvete JJ, Sanz L, Ekwall H \& RodríguezMartínez H 2006 Immunolocalization and possible functional role of PSP-I/PSP-II heterodimer in highlyextended boar spermatozoa. Journal of Andrology 27 766-773.

Calvete J, Ensslin M, Mburu J, Iborra A, Martínez P, Adermann K, Waberski D, Sanz L, Töpfer-Petersen E, Weitze K-F, Einarsson S \& Rodriguez-Martínez H 1997 Monoclonal antibodies against boar sperm zona pellucida-binding protein $\mathrm{AWN}-1$. Characterization of a continuous antigenic determinant and immunolocalization of AWN epitopes in inseminated sows. Biology of Reproduction 57 735-742.

Calvete JI, Sanz L, Ennslin M \& Töpfer-Petersen E 1996 Sperm surface proteins. Reproduction in Domestic Animals 31 101-105.

Calvete IJ, Sanz L, Garcia EM, Caballero I, Parrilla I, Martinez EA, Roca I, Vazquez JM, Saravia F, Wallgren M, Johannisson A \& Rodriguez-Martinez H 2005 On the biological function of boar spermadhesin PSP-1/ PSP-II. Reproduction in Domestic Animals 40331 (W3.1).

Campanero-Rhodes MA, Menendez M, Saiz JL, Sanz L, Calvete JJ \& Solis D 2005 Analysis of the stability of the spermadhesin PSP-I/PSP-II heterodimer. Effects of $\mathrm{Zn}^{2+}$ and acidic pH. FEBS Journal 272 5663-5670.

Centurión F, Vazquez IM, Calvete JJ, Roca J, Sanz L, Parrilla I, Garcia EM \& Martinez EA 2003 Influence of porcine spermadhesins on the susceptibility of boar spermatozoa to high dilution. Biology of Reproduction 69 640-646.

Chen DY, Zhu MY, Cui YD \& Huang TH 2007 Relationships between contents of lipocalin-type prostaglandin $D$ synthase on the surface of infertility sperm and in seminal plasma. Biochemistry 72 215-218.

Claus R 1990 Physiological role of seminal components in the reproductive tract of the female pig. Journal of Reproduction and Fertility Supplement 40 117-31.

Claus R, Moshammer T, Aumüller R \& Weiler $U$ 1989 Replenishment of Al-doses wih oestrogens in physiological amounts: effect on sow prolificacy in a field trial. Zentrablatt furVeterinärmedicin $A$ $36797-800$.

Crabo B \& Einarsson S 1971 Fertility of deep frozen boar spermatozoa. Acta Veterinaria Scandinavica 12 125-127.

Cremades T, Roca J, Rodriguez-Martinez H, Abaigar T, Vazquez IM \& Martinez EA 2005 Kinematic changes during the cryopreservation of boar spermatozoa. Journal of Andrology 26 610-618.

De Graaf SP, Leahy T, Marti J, Evans G \& Maxwell WMC 2008 Application of seminal plasma in sexsorting and sperm cryopreservation. Theriogenology 70 1360-1363.

Druart X, Gatti JL, Huet S, Dacheux JL \& Humblot P 2009 Hypotonic resistance of boar spermatozoa: sperm subpopulations and relationship with epididymal maturation and fertility. Reproduction 137 205-213.

Einarsson S \& Viring S 1973 Distribution of frozenthawed spermatozoa in the reproductive tract of gilts at different time intervals after insemination. Journal of Reproduction and Fertility 32 117-120.

Einarsson S 1971 Studies on the composition of epididymal contents and semen in the boar. Acta Veterinaria Scandinavica Supplement 36 1-80.

Eriksson BM, Vazquez JM, Martinez EA, Roca J, Lucas X \& Rodriguez-Martinez H 2001 Effects of holding time during cooling and of type of package on plasma membrane integrity, motility and in vitro oocyte penetration ability of frozen-thawed boar spermatozoa. Theriogenology 55 1593-1605.

Flower DR 1996 The lipocalin protein family: structure and function. Biochemical Journal 318 1-14.

Flowers WL \& Esbenshade KL 1993 Optimizing management of natural and artificial matings in swine. Journal of Reproduction and Fertility Suppl $48217-228$.

Flowers WL 1995 Relationships between seminal plasma proteins and boar fertility. In: Department of Animal Science Annual Swine Report pp 22-27Ed See MT Raleigh, North Carolina State University.

Flowers WL 1997 Management of boars for efficient production. Journal of Reproduction and Fertility Suppl 52 67-78.

Flowers WL 2008 Genetic and phenotypic variation in reproductive traits of $\mathrm{Al}$ boars. Theriogenology $\mathbf{7 0}$ 1297-1303.

Fouchecourt S, Charpigny G, Reinaud P, Dumont P \& Dacheux JL 2002 Mammalian lipocalin-type prostaglandin D2 synthase in the fluids of the male genital tract: putative biochemical and physiological functions. Biology of Reproduction 66 458-467.

Foxcroft GR, Dyck MK, Ruiz-Sanchez A, Novak S \& Dixon WT 2008 Identifying useable semen. Theriogenology 70 1324-1336.

García EM, Vázquez JM, Parrilla I, Ortega MD, Calvete JJ, Sanz L, Martínez EA, Roca J \& Rodríguez-Martínez H 2008 Localization and expression of spermadhesin PSP-I/PSP-II subunits in the reproductive organs of the boar. International Journal of Andrology 31 $408-417$. 
Gatti JL, Chevrier C, Paquignon M \& Dacheaux IL 1993 External ionic conditions, internal $\mathrm{pH}$ and motility of ram and boar spermatozoa. Journal of Reproduction and Fertility 98 439-449.

Gerena RL, Irikura D, Urade Y, Eguchi N, Chapman DA \& Killian GJ 1998 Identification of a fertility-associated protein in bull seminal plasma as lipocalin-type prostaglandin D synthase. Biology of Reproduction 58 826-833.

Gerner W, Käser T \& Saalmüller A 2009 Porcine T lymphocytes and NK cells - An update. Developmental Comparative Immunology 33 310-320.

Henning $H$, Petrunkina AM, Harrison RAP, Medler Y \& Waberski D 2008 Modulation of boar sperm cesponse to bicarbonate during liquid storage. Theriogenology 70 1393-1394.

Hernandez M, Roca J, Calvete Jl, Sanz L, Muiño-Blanco T, Cebrian-Perez JA, Vazquez JM \& Martinez EA 2007 Cryosurvival and in vitro fertilizing capacity postthaw is improved when boar spermatozoa are frozen in the presence of seminal plasma grom good freezer boars. journal of Andrology 28 689-697.

Hunter RHF \& Rodriguez-Martinez H 2004 Capacitation of mammalian spermatozoa in vivo, with a specific focus on events in the Fallopian tubes. Molecular Reproduction and Development 67 243-250.

Iwamoto T, Hiroaki H, Furuichi Y, Wada K, Satoh M, Satoh M, Osada T \& Gagnon C 1995 Cloning of boar SPMI gene is expressed specifically in seminal vesicles and codes for a sperm motility inhibitor protein. FEBS Letters 368 420-424.

Iwamoto $T$, Tsang A, Luterman $M$, Dickson J, de Lamirande $E$, Okuno $M$, Mohri $H$ \& Gagnon $C$ 1992 Purification and characterization of a sperm motility-synein ATPase inhibitor from boar seminal plasma. Molecular Reproduction and Development 31 55-62.

Jiwakanon J, Persson E \& Dalin AM 2006 The influence of pre- and post-ovulatory insemination and early pregnancy on the infiltration by cells of the immune system in the sow oviduct. Reproduction in Domestic Animals 41 455-466.

Kaeoket K, Persson E \& Dalin AM 2003 Influence of pre-ovulatory insemination and early pregnancy on the infiltration by cells of the immune system in the sow endometrium. Animal Reproduction Science 75 55-71.

Kirkwood RN, Vadnais ML \& Abad M 2008 Practical application of seminal plasma. Theriogenology 70 1364-1367.

Kvist U, Kjellberg S, Björndahl L, Soufir JC \& Arver S 1990 Seminal fluid from men with agenesis of the Wolffian ducts: Zinc binding properties and effects on sperm chromatin stability. International journal of Andrology 13 245-252.

Kvist U, Rodriguez-Martinez H \& Plöen L. 1987 Is the ejaculated boar sperm chromatin stability determined by the presence of Zinc in the seminal plasma? Proceedings of the 7th Workshop Development and Function of the Reproductive Organs, Turku, Finland I: 12.
Langendijk P, Soede NM \& Kemp B 2005 Uterine activity, sperm transport, and the role of boar stimuli around insemination in sows. Theriogenology 63 500-513.

Larsson K \& Einarsson S 1976 Fertility of deep frozen boar spermatozoa: influence of thawing diluents and of boars. Acta Veterinaria Scandinavica 17 46-62.

Lavon U \& Boursnell JC 1975 The split ejaculate of the boar: contributions of the epididymides and seminal vesicles. Journal of Reproduction and Fertility 42 541-552.

Leone MG, Haq HA \& Saso L 2002 Lipocalin type prostaglandin D-synthase: which role in male fertility? Contraception 65 293-295.

Leshin LS, Raj SMP, Smith CK, Kwok SCM, Kreling RR \& Li WI 1998 Immunostimulatory effects of pig seminal proteins on pig lymphocytes. Journal of Reproduction and Fertility $11477-84$.

Lovell JE \& Getty R 1968 Fate of semen in the uterus of the sow: histologic study of endometrium during the 27 hours after natural service. American lournal of Veterinary Research 29 609-625.

Mann T \& Lutwak-Mann C 1981 Male Reproductive Function and Semen. First edition. New York: Springer-Verlag Berlin Heidelberg.

Marchese S, Pes D, Scaloni A, Carbone V \& Pelosi P 1998 Lipocalins of boar salivary glands binding odours and pheromones. European Journal of Biochemistry 252 563-568.

Massanyi P, Trandzik J, Nad P, Toman R, Skalicka M \& Korenekova B 2003 Seminal concentrations of trace elements in various animals and their correlations. Asian Journal of Andrology 5 101-104.

Matthijs A, Engel B \& Woelders H 2003 Neutrophil recruitment and phagocytosis of boar spermatozoa after artificial insemination of sows, and the effects of inseminate volume, sperm dose and specific additives in the extender. Reproduction 125 357-367.

Moore HDM \& Hibbitt KG 1977 Fertility of boar spermatozoa after freezing in the absence of seminal vesicular proteins. Journal of Reproduction and Fertility 50 349-352.

Murray FA \& Grifo APJ 1983 Increased litter size in gilts by intrauterine infusion of seminal and sperm antigens before breeding. Journal of Animal Science 56 895-900.

O Leary S, Jasper MJ, Robertson SA \&Armstrong DT 2006 Seminal plasma regulates ovarian progesterone production, leukocyte recruitment and follicular cell responses in the pig. Reproduction 132 147-158.

O Leary S, Jasper MJ, Warnes GM, Armstrong DT \& Robertson SA 2004 Seminal plasma regulates endometrial cytokine expression, leukocyte recruitment and embryo development in the pig. Reproduction 128 237-247.

Peña FJ, Saravia F, García-Herreros M, Núñez I, Tapia JA, Johannisson A, Wallgren M \& Rodríguez Martínez H 2005 Identification of sperm morphological subpopulations in two different portions of the boar ejaculate and its relation to post thaw quality. Journal of Andrology 26 716-723. 
Peña FJ, Saravia F, Núñez-Martínez I, Johannisson A, Wallgren M \& Rodriguez-Martinez H 2006 Do different portions of the boar ejaculate vary in their ability to sustain cryopreservation? Animal Reproduction Science 93 101-113.

Popwell JM \& Flowers WL 2004 Variability in relationships between semen quality and estimates of in vivo and in vitro fertility in boars. Animal Reproduction Science $8197-113$.

Pursel VG, Johnson LA \& Schulman LL 1973 Effect of dilution, seminal plasma, and incubation period on cold shock susceptibility of boar spermatozoa. Journal of Animal Science 37 528-531.

Reed HC 1985 Current use of frozen boar semen - future need of frozen boar semen. In: Deep Freezing of Boar Semen pp 225-237 Eds L.A Johnson \& K Larsson, SLU,Uppsala, Sweden.

Robertson SA 2007 Seminal fluid signalling in the female reproductive tract: lessons from rodents and pigs. Journal of Animal Science 85 E36-44.

Robertson SA, Ingman WV, $O$ 'Leary S, Sharkey DJ \& Tremellen KP 2002 Transforming growth factor beta - a mediator of immune deviation in seminal plasma. lournal of Reproductive Immunology 57 109-128.

Roca J, Hernández $M$, Carvajal G, Vázquez JM \& Martínez EA 2006 Factors influencing boar sperm cryosurvival. Journal of Animal Science 842692 -2699 .

Rodriguez-Martinez H 1991 Aspects of the electrolytic composition of boar epididymal fluid with reference to sperm maturation and storage. In: Boar semen preservation II pp13-27 Eds L Johnson \& D Rath Reproduction in Domestic Animals Supplement 1 13-27.

Rodriguez-Martinez H 2007a Reproductive biotechnology in pigs: what will remain? In: Paradigms in pig science" Chapter 15 pp 263-302. Eds J Wiseman, MA Varley, S McOrist \& B Kemp. Nottingham University Press, Nottingham, UK, (ISBN 978-1-904761-56-3).

Rodriguez-Martinez $\mathbf{H} 2007 \mathrm{~b}$ Role of the oviduct in sperm capacitation. Theriogenology 68 138-146.

Rodriguez-Martinez H, Courtens IL, Kvist U \& Plöen L 1990a Immunocytochemical localization of nuclear protamine in boar spermatozoa during epididymal transit. Journal of Reproduction and Fertility 89 591-595.

Rodriguez-Martinez H, Ekstedt E \& Einarsson S 1990b Acidification of the epididymal fluid in the boar. International journal of Andrology 13 238-243.

Rodriguez-Martinez H, Ekwall H, Kvist U, Malmgren L \& Plöen L 1987 X-ray microanalysis of boar spermatozoa: changes in the elemental composition at ejaculation. Proceedings $40^{\text {th }}$ Annual Meeting SCANDEM, Bergen Norway 134.

Rodríguez-Martínez H, Iborra A, Martínez P \& Calvete J) 1998 Immunoelectronmicroscopic imaging of spermadhesin AWN epitopes on boar spermatozoa bound in vivo to the zona pellucida. Reproduction Fertility \& Development 10 491-497.

Rodriguez-Martinez H, Nicander L, Viring S, Einarsson S \& Larsson K 1990c Ultrastructure of the uterotubal junction in preovulatory pigs. Anatomia, Histolologia Embryologia 19 16-36.

Rodríguez-Martinez $H$, Saravia $F$, Wallgren $M$, Roca J, Peña FJ 2008 Influence of seminal plasma on the kinematics of boar spermatozoa during freezing. Theriogenology 70 1242-1250.

Rodriguez-Martinez $H$, Saravia $F$, Wallgren $M$, Tienthai P, Johannisson A, Vázquez JM, Martínez E, Roca J, Sanz L \& Calvete Jf 2005 Boar spermatozoa in the oviduct. Theriogenology 63 514-535.

Rodriguez-Martinez H, Tienthai P, Suzuki K, Funahashi $H$, Ekwall H \& Johannisson A 2001 Oviduct involvement in sperm capacitation and oocyte development. Reproduction Supplement 58 129-145.

Rozeboom KJ, Rocha-Chavez G \& Troedsson MH 2001b Inhibition of neutrophil chemotaxis by pig seminal plasma in vitro: a potential method for modulating post-breeding inflammation in sows. Reproduction $121567-572$.

Rozeboom KJ, Troedsson MH \& Crabo BG 1998 Characterization of uterine leukocyte infiltration in gilts after artificial insemination. Journal of Reproduction and Fertility 114 195-199.

Rozeboom KJ, Troedsson MH, Hodson HH, Shurson GC \& Crabo BG 2000 The importance of seminal plasma on the fertility of subsequent artificial inseminations in swine. Journal of Animal Science 78 443-448.

Rozeboom KJ, Troedsson MH, Molitor TW \& Crabo BG 1999 The effect of spermatozoa and seminal plasma on leukocyte migration into the uterus of gilts. Journal of Animal Science 77 2201-2206.

Rozeboom KI, Troedsson MH, Rocha GR \& Crabo BG 2001a The chemotactic properties of porcine seminal components toward neutrophils in vitro. lournal of Animal Science 79 996-1002.

Saravia F 2008 Cryopreservation of boar semen: Impact of the use of specific ejaculate portions, concentrated packaging and simplified freezing procedures on sperm cryosurvival and potential fertilising capacity", Acta Universitatis agriculturae Sueciae 2008:98 1-69.

Saravia F, Hernández M, Wallgren MK, Johannisson A \& Rodríguez-Martínez $\mathrm{H}$ 2007a Cooling during semen cryopreservation does not induce capacitation of boar spermatozoa. International fournal of Andrology $\mathbf{3 0}$ 485-499.

Saravia $F, M$ Wallgren, A Johannisson, If Calvete, $L$ Sanz, FJ Peña, I Roca \& Rodríguez-Martínez H 2009a Exposure to the seminal plasma of different portions of the boar ejaculate modulates the survival of spermatozoa cryopreserved in MiniflatPacks. Theriogenology 71 662-675.

Saravia F, M Wallgren \& Rodríguez-Martínez H 2009b Freezing of boar semen can be simplified by handling a specific portion of the ejaculate with a shorter procedure and MiniFlatPack packaging. Animal Reproduction Science (in press).

Saravia F, Núñez-Martínez I, Morán JM, Soler C, Muriel A, Rodríguez-Martínez H \& Peña FJ 2007b Differences in boar sperm head shape and dimensions recorded by computer-assisted sperm morphometry are not related to chromatin integrity. Theriogenology 68 196-203. 
Schuberth H], Taylor U, Zerbe H, Waberski A, Hunter R \& Rath D 2008 Immunological responses to semen in the female genital tract. Theriogenology $701174-1181$.

Sellés E, Wallgren M, Gadea J, Ruiz S \& RodriguezMartinez H 2001 Sperm viability and capacitation-like changes in fractions of boar semen after storage and freezing. Proceedings VI Int Conf Pig Reproduction. Columbia, Missouri USA, June 3-6 2001 I 51.

Senger PL 2005 Pathways to pregnancy and parturition. $2^{\text {nd }}$ revised version, Current Conceptions inc, Pullman, WA, USA, ISBN 0-9657648-2-6.

Steverink DWB, Soede NM, Bouwman EG \& Kemp B 1998 Semen backflow after insemination and its effect on fertilisation results in sows. Animal Reproduction Science 54 109-119.

Summers PM \& Pena Jr ST 2008 Seminal vesicle fluid reduces binding of porcine epididymal spermatozoa to oviduct implants. Theriogenology 70 1387-1388.

Taylor U, Rath D, Zerbe H \& Schuberth H] 2008 Interaction of intact porcine spermatozoa with epithelial cells and neutrophilic granulocytes during uterine passage. Reproduction in Domestic Animals 43 166-175.

Taylor U, Schuberth HJ, Rath D, Michelmann HW, Sauter-Louis C \& Zerbe H 2009 Influence of inseminate components on porcine leukocyte migration in vitro and in vivo after pre- and post-ovulatory insemination. Reproduction in Domestic Animals 44 180-188.

Tienthai P, Johannisson A \& Rodriguez-Martínez H 2004 Sperm capacitation in the porcine oviduct. Animal Reproduction Science 80 131-146.

Töpfer-Petersen E, Romero A, Varela PF, EkhlasiHundrieser M, Dostàlovà Z, Sanz L \& Calvete JJ 1998 Spermadhesins: a new protein family. Facts, hypotheses and perspectives. Andrologia 30 217-224.

Vadnais ML, Kirkwood RN, Specher DJ \& Chou K 2005 Effects of extender, incubation temperature, and added seminal plasma on capacitation of cryopreserved, thawed boar sperm as determined by chlortetracycline staining. Animal Reproduction Science 90347 -354.
Veselsky L, Cechova D, Hoskova M, Stedra J, Holan V \& Stanek R 1991 In vivo and in vitro imunosuppression by boar seminal vesicle fluid fraction. International lournal of Andrology 36 183-188.

Veselsky L, Stanek R \& Hradecky J 1981 Effect of antibodies to boar spermatozoa on fertility in sows and rabbits. Archives of Andrology 7 337-342.

Viring S \& Einarsson S 1981 Sperm distribution within the genital tract of naturally inseminated gilts. Nordisk Veterinär Medicin 33 145-149.

Viring S 1980 Distribution of live and dead spermatozoa in the genital tract of gilts at different times after insemination. Acta Veterinaria Scandinavica 21 587-597.

Waberski D, Döhring A, Ardon F, Ritter N, Zerbe $H$, Schuberth HJ, Hewicker-Trautwein M, Weitze KF \& Hunter RH 2006 Physiological routes from intrauterine seminal contents to advancement of ovulation. Acta Veterinaria Scandinavica 4813.

Wagner HG \& Thibier M 2000 World statistics for artificial insemination in small ruminants and swine. Proceedings $14^{\text {th }}$ International Congress on Animal Reproduction Stockholm 2 15:3.

Xu X, Ding J, Seth PC, Habison DS \& Foxcroft GR 1996 In vitro fertilization of in vitro matured pig oocytes: effects of boar and ejaculate fraction. Theriogenology $45745-755$.

Xu X, Pommier S, Arbov T, Hutchings B, Sotto W \& Foxcroft GR 1998 In vitro Maturation and fertilization techniques for assessment of semen quality and boar fertility. Journal of Animal Science 76 3079-3089.

Yang WC, Kwok SCM, Leshin S, Bollo E \& LI WI 1998 Purified porcine seminal plasma protein enhances in vitro immune activities of porcine peripheral lymphocytes. Biology of Reproduction 59 202-207.

Zhu J, Xu X, Ding J, Cosgrove JR \& Foxcroft GR 2000 Effects of semen plasma from different fractions of individual ejaculates on IVF in pigs. Theriogenology 54 1443-1452. 